ARTICLE

\title{
HSL1 and BAM1/2 impact epidermal cell development by sensing distinct signaling peptides
}

\author{
Andra-Octavia Roman (1) 1,3, Pedro Jimenez-Sandoval (1) 1,3, Sebastian Augustin (1) ${ }^{1}$, Caroline Broyart ${ }^{1}$, \\ Ludwig A. Hothorn ${ }^{2} \&$ Julia Santiago (1) ${ }^{1 凶}$
}

The membrane receptor kinases HAESA and HSL2 recognize a family of IDA/IDL signaling peptides to control cell separation processes in different plant organs. The homologous HSL1 has been reported to regulate epidermal cell patterning by interacting with a different class of signaling peptides from the CLE family. Here we demonstrate that HSL1 binds IDA/IDL peptides with high, and CLE peptides with lower affinity, respectively. Ligand sensing capability and receptor activation of HSL1 require a SERK co-receptor kinase. Crystal structures with IDA/IDLs or with CLE9 reveal that HSL1-SERK1 complex recognizes the entire IDA/IDL signaling peptide, while only parts of CLE9 are bound to the receptor. In contrast, the receptor kinase BAM1 interacts with the entire CLE9 peptide with high affinity and specificity. Furthermore, the receptor tandem BAM1/BAM2 regulates epidermal cell division homeostasis. Consequently, HSL1-IDLs and BAM1/BAM2-CLEs independently regulate cell patterning in the leaf epidermal tissue.

\footnotetext{
${ }^{1}$ The Plant Signaling Mechanisms Laboratory, Department of Plant Molecular Biology, University of Lausanne, 1015 Lausanne, Switzerland. ${ }^{2}$ Institute of Biostatistics, Leibniz University, 30167 Hannover, Germany. ${ }^{3}$ These authors contributed equally: Andra-Octavia Roman, Pedro Jimenez-Sandoval.

凶email: julia.santiago@unil.ch
} 
P lant peptide hormones have emerged as key players in cellto-cell communication. They coordinate plant immunity, development, and adaptations to an ever-changing environment ${ }^{1}$. To sense sequence-diverse signaling molecules, plants have evolved unique membrane receptor kinases. LeucineRich Repeat Receptor Kinases (LRR-RKs) represent the largest class of membrane receptor kinases in plants ${ }^{2}$. Their cognate peptide ligands are processed from larger preproteins and can be post-translationally modified ${ }^{1,3}$, for example by tyrosine sulfation, proline hydroxylation (Hyp), and hydroxyproline arabinosylation. These modifications may regulate the diffusion, stability and bioactivity of the peptide hormone, by for example allowing for the specific recognition by their cognate LRR-RK ${ }^{4-8}$.

INFLORESCENCE DEFICIENT IN ABSCISSION (IDA) and IDA-LIKE (IDL) are a family of dodeca hydroxyprolinated peptides that are sensed by the LRR-RKs HAESA (HAE) and HAESA-LIKE 2 (HSL2) involved in regulating cell separation events, such as organ shedding and root cap sloughing ${ }^{4,9-12}$. SOMATIC EMBRYOGENESIS RECEPTOR KINASE (SERK) proteins act as co-receptors mediating high-affinity ligand sensing and receptor complex activation $^{4,13,14}$. In the HAE-IDA-SERK1 complex structure, a central hydroxyproline anchors the IDA peptide to the peptidebinding pocket in $\mathrm{HAE}^{4}$. IDA/IDL peptides are sequence related to the well-studied CLAVATA3/EMBRYO SURROUNDING REGION-RELATED (CLE) peptide family consisting of 27 members ${ }^{15}$. CLEs also undergo post-translational modifications such as proline hydroxylation and arabinosylation ${ }^{8,16-18}$ that regulate peptide bioactivity ${ }^{19}$. CLE peptides have been implicated in shoot stem cell homeostasis, root xylem development, root protophloem differentiation, vascular cambium activity, and stomata formation $8,16,20-22$, and are recognized by different LRRRKs $s^{6,17,21,23-26}$. The LRR-RK BARELY ANY MERISTEM 1 (BAM1) and its homolog BAM2 sense $\mathrm{CLV}^{27}$ and other CLE peptides with nanomolar affinities ${ }^{6,26}$, and coordinate formative root divisions, male gametophyte development, root xylem patterning and meristems development ${ }^{21,26-28}$. CLAVATA3 INSENSITIVE RECEPTOR KINASES (CIKs) ${ }^{29}$ have been genetically described as the co-receptors for CLV1 and BAMs. Recently, CLE9 has been proposed to act as a dual ligand for the LRR-RKs BAM1 and HAESA-LIKE 1 (HSL1), to regulate root xylem file number and stomatal cell lineage development, respectively ${ }^{21,22}$. With respect to its role in stomatal development, the CLE9 sensing system has been reported to operate independently from the well-characterized ERECTA (ER) - EPIDERMAL PATTERNING FACTORs (EPFs) SERK signaling pathway ${ }^{21,30-35}$, suggesting the existence of additional regulatory layers in the control of epidermal cell development.

Following up on our previous work on HAE-IDA/IDL-SERK interaction, we characterize how the related HSL1 receptor can discriminate between IDA/IDLs and the sequence-related CLE peptide family members. Here we report that HSL1 is a bona-fide receptor for IDA/IDL peptides that have evolved a specific binding surface for high-affinity recognition of all IDA/IDL family members. In contrast, the sequence-related CLE9 peptide is sensed by the LRR-RK BAM1 with high affinity and specificity. At the physiological level, we find that HSL1-IDLs and BAM1/ BAM2-CLEs control different aspects of leaf epidermal cell patterning. Structural analysis of HSL1-IDL/CLE9 and BAM1-CLE9 complexes reveals how two families of LRR-RKs have evolved to specifically sense two distinct, yet sequence-related, signaling peptide families.

\section{Results}

It has been previously reported that the LRR-RKs HAE and HSL2 specifically bind IDA and other IDL peptides to regulate abscission and cell separation processes $4,10-12$. To characterize the sequence-related HSL1 receptor, we determined the crystal structure of the apo HSL1 ectodomain at $1.83 \AA$ resolution (Supplementary Fig. 1 and Supplementary Table 1). HSL1 folds into a superhelical assembly of 21 LRRs with a conserved ligandbinding surface (Supplementary Fig. 1), suggesting a shared peptide recognition mechanism with the receptors HAE/HSL2. We next investigated whether HSL1 can sense IDA/IDL peptides and form a ternary complex with the co-receptor protein SERK1 ${ }^{4,14}$. HSL1 forms stable heterodimeric complexes with SERK1 in the presence of IDA/IDL peptides in analytical sizeexclusion chromatography experiments (SEC) (Supplementary Fig. 1). To quantify these interactions, we titrated IDA and IDL peptides into a solution containing isolated HSL1 ectodomain, using isothermal titration calorimetry (ITC). We found that IDA and IDL1-4 bind to the HSL1 receptor-ligand pocket with high affinity, ranging from $120 \mathrm{nM}$ to $2 \mu \mathrm{M}$ (Fig. 1a and Supplementary Fig. 2). We next assessed the contribution of SERK1 to IDA/ IDLs recognition by HSL1. Our calorimetry experiments reveal that SERK1 binds HSL1 in the presence of IDA/IDL peptides with a dissociation constant $\left(K_{\mathrm{d}}\right)$ of around 15 to $50 \mathrm{nM}$, indicating that IDA/IDLs promote a high-affinity association between HSL1 and the co-receptor SERK1 (Fig. 1b and Supplementary Fig. 3). In contrast, we did not detect binding of CLE9 to the isolated ectodomain of HSL1 in ITC assays. Similarly, we could not detect binding with other CLE family members such as CLV3 or the CLE9 sequence-related CLE13 (Fig. 1a and Supplementary Fig. 2). In the presence of the co-receptor SERK1, we did observe CLE9 binding to HSL1 with a dissociation constant of $400 \mathrm{nM}$. In the case of CLV3 and CLE13 no biding was detected in the presence of SERK1 (Fig. 1b and Supplementary Fig. 3).

We next determined binding kinetic parameters for HSL1 vs. IDA peptides and the co-receptor SERK1 in grating-coupled interferometry (GCI) assays ${ }^{36,37}$. GCI experiments yielded similar $K_{\mathrm{d}} \mathrm{s}$ between HSL1 and IDA peptides, and with the SERK coreceptor (Fig. 1c-d and Supplementary Fig. 4). The interaction between the co-receptor and HSL1 in the presence of the IDA ligands is defined by a fast association $\left(k_{a} \sim 1.6 \times 10^{4} \mathrm{M}^{-1} \mathrm{~s}^{-1}\right)$ and a very slow dissociation rate $\left(k_{\mathrm{d}} \sim 1.5 \times 10^{-4} \mathrm{~s}^{-1}\right)$ (Fig. $1 \mathrm{~d}$ and Supplementary Fig. 4). Taken together, our quantitative binding experiments demonstrate that HSL1 is a bona-fide IDA/ IDLs receptor and uses SERK proteins as co-receptor kinases for high-affinity ligand sensing.

The vastly different binding affinities between IDA/IDLs vs. CLE9 to HSL1 prompted us to determine co-crystal structures of four HSL1-IDA/IDL-SERK1 ternary complexes with: IDA, IDL1, IDL2, and IDL3 (at $2.31 \AA, 2.38 \AA, 2.20 \AA$, and $2.70 \AA$, respectively) and the HSL1-CLE9-SERK1 complex at $2.87 \AA$ (Supplementary Fig. 5 and Supplementary Table 1). We first validated our HSL1-IDASERK1 structural model, by mutating key amino acids in the HSL1 ligand-binding surface and its interface with SERK1. Size-exclusion chromatography experiments of HSL1 mutants: HSL1 Y261AR402A (ligand pocket) and HSL1 ${ }^{\text {N543AY544AN566A }}$ (receptor-co-receptor zipper-like interface), disrupted the formation of the ternary complex (Supplementary Fig. 6). The corresponding mutations in HAE

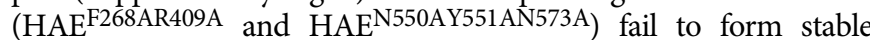
signaling complexes and did not restore floral abscission in the hae hsl 2 mutant background (Supplementary Fig. 6 and Supplementary Fig. 7), suggesting that HSL1 shares a common peptide recognition mechanism with other HAE-type receptors.

In agreement with our biochemical assays, the crystal structures revealed that all IDA/IDL peptides specifically bind to the peptide-binding surface of HSL1. IDA/IDLs adopt a fully extended conformation in the structure (Fig. 2a and Supplementary Fig. 5). The co-receptor SERK1 interacts with the C-terminal region of the different IDA/IDL peptides (residues 68-69 in IDA), completing the peptide-binding pocket using its $\mathrm{N}$-terminal loop 
a
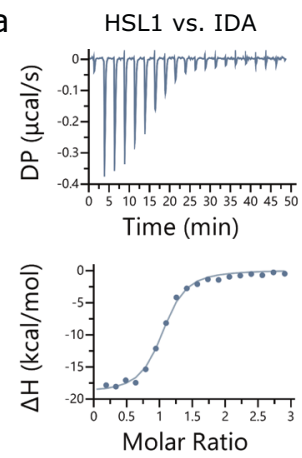

b

HSL1-IDA vS. SERK1
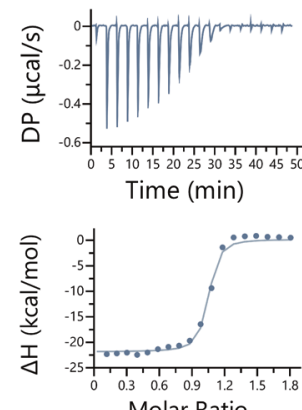

c

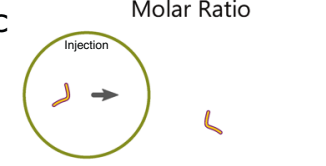

\begin{tabular}{lllll} 
Ligand $_{\text {(syringe) }}$ & Protein $_{(\text {cell) }}$ & $\mathrm{K}_{d(\mathrm{nM})}$ & $\Delta \mathrm{H}_{(\mathrm{kcal} / \mathrm{mol})}$ & $\mathrm{N}$ \\
\hline IDA & HSL1 & $400 \pm 7$ & $-20 \pm 2$ & 1 \\
IDL1 & HSL1 & $590 \pm 30.4$ & $-15 \pm 2$ & 1 \\
IDL2 & HSL1 & $121 \pm 19.8$ & $-17 \pm 0.5$ & 1 \\
IDL3 & HSL1 & $690 \pm 315$ & $-16 \pm 2$ & 1 \\
IDL4 & HSL1 & $2020 \pm 205$ & $-12 \pm 1.5$ & 1 \\
CLE9 & HSL1 & n.d & n.d & \\
CLV3 & HSL1 & n.d & n.d & \\
CLE13 & HSL1 & n.d & n.d &
\end{tabular}

\begin{tabular}{lllll} 
Ligand $_{(\text {syringe) }}$ & Protein $_{(\text {cell) }}$ & $\mathrm{K}_{d(\mathrm{nM})}$ & $\Delta \mathrm{H}_{(\mathrm{kcal} / \mathrm{mol})}$ & $\mathrm{N}$ \\
\hline SERK1 & $\mathrm{HSL1}+$ IDA & $22 \pm 7$ & $-22 \pm 4$ & 1
\end{tabular}

SERK1 HSL1 + IDL1 $44 \pm 6 \quad-27 \pm 1 \quad 1$

SERK1 HSL1 + IDL2 $16 \pm 2.5 \quad-18 \pm 5 \quad 1$

SERK1 HSL1 + IDL3 $26 \pm 18 \quad-24 \pm 4 \quad 1$

SERK1 HSL1 + IDL4 $49 \pm 20 \quad-18 \pm 8 \quad 1$

SERK1 HSL1 + CLE9 $400 \pm 73 \quad-24 \pm 3 \quad 1$

SERK1 HSL1 + CLV3 n.d n.d

SERK1 HSL1 + CLE13 n.d n.d

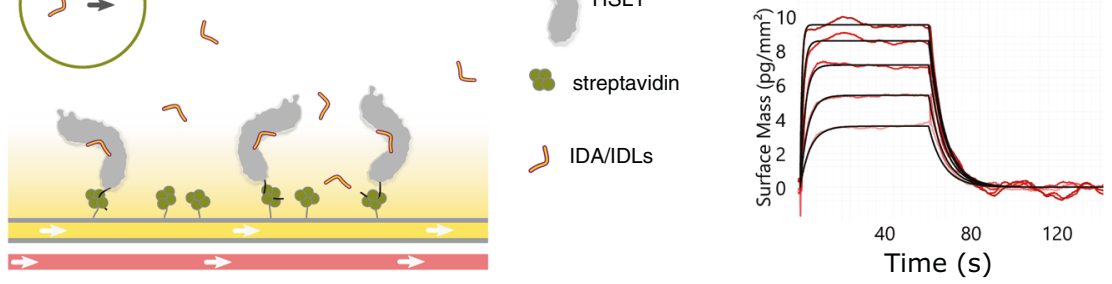

HSL1-IDA vs. SERK1
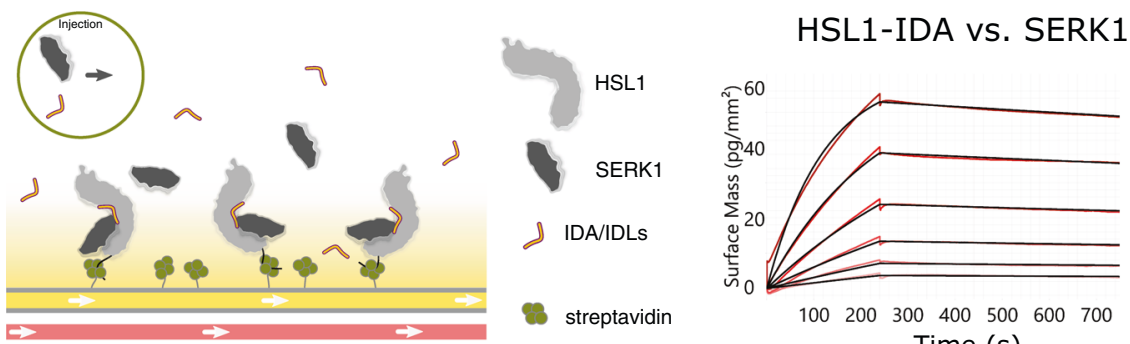

$100 \quad 200 \quad 300 \quad 400 \quad 500 \quad 600 \quad 700$ Time (s)

\begin{tabular}{|c|c|c|c|c|}
\hline Ligand $_{\text {(analyte) }}$ & Receptor $_{\text {(surface) }}$ & $\mathrm{K}_{d(\mathrm{nM})}$ & $\mathrm{k}_{a\left(\mathrm{M}^{-1} \mathrm{~s}^{-1}\right)}$ & $k_{d(s-1)}$ \\
\hline$\overline{\mathrm{IDA}}$ & HSL1 & 580 & $2.25 \times 10^{5}$ & $12.7 \times 10$ \\
\hline IDL3 & HSL1 & 800 & $7 \times 10^{5}$ & $5.5 \times 10^{-1}$ \\
\hline IDL4 & HSL1 & 1850 & $4.6 \times 10^{5}$ & $6.5 \times 10^{-1}$ \\
\hline SERK1 + IDA & HSL1 & 9 & $1.60 \times 10^{4}$ & $1.5 \times 10$ \\
\hline SERK1 + IDL1 & HSL1 & 12.5 & $1.45 \times 10^{4}$ & $1.8 \times 10$ \\
\hline SERK1 + IDL2 & HSL1 & 9 & $1.60 \times 10^{4}$ & $1.5 \times 10$ \\
\hline SERK1 + IDL3 & HSL1 & 1 & $2.25 \times 10^{4}$ & $3 \times 10$ \\
\hline SERK1 + IDL4 & HSL1 & 12.5 & $1.14 \times 10^{4}$ & $1.5 \times 10$ \\
\hline
\end{tabular}

e

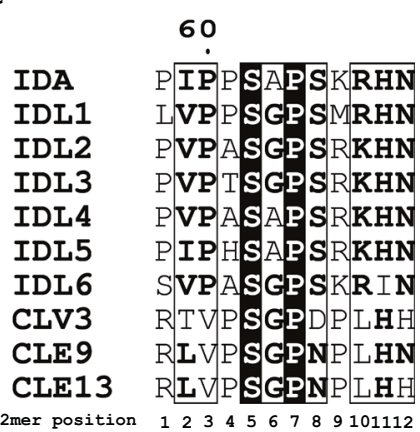

region (Supplementary Fig. 6). Superposition of the four crystal structures yielded an R.M.S.D of $\sim 0.6 \AA$ comparing $590 \mathrm{C} \alpha$ atom pairs, with IDL peptides perfectly aligning to each other (Fig. 2a). Given the high structural similarity among all IDA/IDL ternary complexes, we subsequently used the HSL1-IDA-SERK1 complex to further analyze the distinct ligand recognition mechanism between the IDA/IDLs and CLE peptide families.

Structural superposition of the HSL1-IDA-SERK1 and HSL1CLE9-SERK1 complexes revealed that both IDA and CLE9 bind to the HSL1 peptide-binding surface, however, with the CLE9 
Fig. 1 HSL1 senses IDA/IDL peptides with high affinity and forms a stable complex with the co-receptor SERK1. a ITC binding experiments and summary table of IDA/IDL and CLE peptides versus HSL1 ectodomain. $K_{d}$ (dissociation constant) indicates the binding affinity between the two molecules considered (in nanomolar). The $\mathrm{N}$ indicates the reaction stoichiometry ( $n=1$ for a 1:1 interaction). The values indicated in the table are the mean \pm SD of at least two independent experiments. b Contribution of the SERK1 co-receptor to the HLS1-IDA/IDLs and HSL1-CLE ternary complex formation. ITC experiments and results table of titrating SERK1 protein into a solution containing HSL1 and the indicated peptide. c Schematic overview of the GCI binding experiments. Experiments were done using Avi-tag-based coupling. Streptavidin (in green) was immobilized using direct amine coupling to the chip. Next, the biotinylated ectodomain of HSL1 was captured by streptavidin. IDA/IDLs (top) or SERK1 + IDA/IDLs (bottom) were used as analytes in the different experiments. Binding kinetics of HSL1 receptor vs. IDA, and HSL1-IDA complex vs. SERK1 obtained from GCl experiments. The sensograms with recorded data are shown in red with the respective fits in black. $\mathbf{d} \mathrm{GCl}$ summary table of HSL1 vs. IDA/IDLs and contribution of SERK1 to the kinetics of the ternary complex formation. The table contains the corresponding association rate constant $\left(k_{\mathrm{a}}\right)$, dissociation rate constant $\left(k_{\mathrm{d}}\right)$, and the dissociation constant $K_{\mathrm{d}}$ from experiments reported in Supplementary Fig. 4. e Sequence alignment of the mature peptides of IDA/IDLs, and CLE9, CLV3, and CLE13.

N-terminus (residues 109-112) adopting a radically different orientation compared to IDA and IDLs (Fig. $2 \mathrm{~b}$ and Supplementary Fig. 5). While the proline-rich N-terminus of IDA/IDLs accommodate into the hydrophobic cavity of the HSL1 binding surface (Supplementary Fig. 6), the corresponding region of CLE9 is unable to bind and found shifted $10 \AA$ away from the binding groove in our structure (Fig. 2b). The lack of receptor-peptide interaction in this region is supported by the poorly defined electron density and the high atomic displacement parameters (B-factors) that indicate high flexibility of the CLE9 N-terminus (Fig. 2c and Supplementary Fig. 5). Taken together, HSL1 can sense the full mature IDA/IDL peptides but not CLE9, with major structural differences found in the N-terminus of the two peptide families.

We next analyzed the structural differences in the peptides core motifs. The IDA core motif contains three conserved amino acids $\left(\right.$ Ser62 ${ }^{\mathrm{IDA}}$, Hyp64 ${ }^{\mathrm{IDA}}$, and Ser65 ${ }^{\mathrm{IDA}}$ ) that are specifically recognized by the receptor through a network of direct and watermediated hydrogen bonds that anchor the peptide to the receptor (Fig. 2d and Supplementary Fig. 5). Removal of the hydroxyl group of the central Pro64 in IDA results in the loss of binding to HSL1 and disrupts the formation of the ternary complex (Fig. $2 \mathrm{f}$ and Supplementary Fig. 8$)^{4}$. In line with this, plants expressing the IDA Hyp64Gly mutant protein under the expression of the IDA promoter failed to rescue the abscission defect of the loss-offunction ida mutant, in contrast to the wild-type IDA (Fig. $2 \mathrm{~g}$ and Supplementary Fig. 6). These results highlight the relevance of the peptide core binding region in IDA bioactivity.

CLE9 and IDA/IDL peptides share sequence similarities in their core regions such as the Ser in position five (Ser113 in CLE9) and the Hyp in position 7 (Hyp115 in CLE9) ${ }^{17}$, enabling CLE9 to bind HSL1-SERK1 with lower affinity (Fig. 1a, b). However, Ser65 IDA, which makes direct contacts with Asp283 and Tyr308 in HSL1 (Fig. 2d), is an Asn residue in CLE9 that is unable to interact with the receptor-binding surface (Fig. 2e). Replacing Asn116 ${ }^{\mathrm{CLE} 9}$ to a Ser results in a 2 -fold increase in binding affinity to the HSL1-SERK1 complex and to detectable binding to the isolated HSL1 ectodomain (Fig. 2f and Supplementary Fig. 8).

The C-terminus of IDA/IDL and CLE9 are similar, with the last two residues being conserved (Fig. 1e). This motif interacts with the HSL1 receptor and with the SERK1 N-terminal loop ${ }^{4}$. In this region, receptor-peptide and peptide-co-receptor interactions are mainly mediated by backbone interactions. His $68^{\mathrm{IDA}}$ acts as a bridging point between HSL1 and the SERK1 co-receptor, establishing hydrogen-bonding contacts with Glu376 in HSL1 and with the Asp51 in SERK1 (Supplementary Fig. 6). To assess the contribution of the C-terminal region of IDA to HSL1 binding and co-receptor sensing, we engineered a Lys66/Arg67/ His68 $\rightarrow$ Ala mutant and we tested its efficiency in binding assays. The triple IDA mutant showed $\sim 15$ fold reduced binding affinity to HSL1 and a $\sim 30$-fold $\mathrm{K}_{d}$ reduction in the presence of the coreceptor compared to the wild-type peptide (Fig. $2 \mathrm{f}$ and Fig. $1 \mathrm{a}, \mathrm{b}$ and Supplementary Fig. 8). These results agree with the role of the conserved IDA C-terminus in the control of floral shedding. The triple mutant Lys66/Arg67/His68 $\rightarrow$ Ala introduced in the ida mutant under IDA native's promoter, was not able to complement the delay in floral organ abscission (Fig. $2 \mathrm{~g}$ and Supplementary Fig. 6). Taken together, HSL1 can discriminate between IDA/IDLs and the CLE9 peptide by 'reading' structural differences in the N-terminal and core peptide regions.

LRR-RK BAM1 has been previously implicated in the perception and signaling of CLE peptides ${ }^{27}$, sensing CLE9 with high-

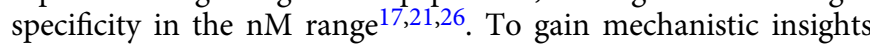
into CLE9 recognition by BAM1, we expressed, purified and crystallized a BAM1-CLE9 complex, but could not obtain diffracting crystals. We thus built a BAM1 homology model using the CLE-receptor PHLOEM INTERCALATED WITH XYLEM (PXY) as a template (Supplementary Fig. 9, see Methods). We docked the CLE9 peptide into the BAM1 model, using highresolution peptide modeling ${ }^{38}$. The docking was performed using three starting peptide orientations based on CLE9 in HSL1, IDA in HSL1 and CLE41 in PXY. Interestingly, all of them converged into a similar minimal-energy elongated peptide conformation that fully accommodated into the BAM1-model binding groove, resembling CLE41 recognition by $\mathrm{PXY}^{25}$ (Supplementary Fig. 9). In our BAM1-CLE9 model, the N-terminal peptide region reveals as the main recognition and docking point to the receptor with a combination of hydrophobic and electrostatic interactions matching the architecture of the receptor pocket (Supplementary Fig. 9). Different from HAE-type receptors, BAM1 has a distinct array of amino acids in its core region, with a highly conserved bulky residue (Phe269 ${ }^{\mathrm{BAM} 1}$, Phe279 $\mathrm{PXY}$ ) disrupting the previously described hydroxyproline and Ser5 coordination sites in HSL1 (Fig. 2d, Supplementary Fig. 7 and Supplementary Fig. 9). Interestingly, unlike IDA/IDLs in HSL1, the central hydroxyproline in CLE9 ${ }^{17}$ does not seem to be coordinated in the BAM1 receptor model, suggesting that is not a determinant peptide feature for receptor recognition (Supplementary Fig. 9).

To validate the structural analysis on our BAM1-CLE9 complex docking model, we engineered CLE9 and IDA variants substituting the different $\mathrm{N}$-terminal residues by the corresponding ones in IDA or CLE9, respectively, and we tested their binding capacities to the BAM1 extracellular domain. Substitutions of the first and second residues in CLE9 did not significantly impact the binding. However, replacement of the third Val by a Pro (CLE9V111P) dramatically reduced the binding affinity compared to the wild-type CLE9 peptide (100 nM vs $3000 \mathrm{nM}$ ) (Fig. 3a and Supplementary Fig. 10). Complete substitution of the $\mathrm{N}$-terminal region in CLE9 (CLE9 ${ }^{\mathrm{R} 109 \mathrm{PL} 110 \mathrm{IV} 111 \mathrm{P})}$ ) led to nondetectable binding. On the other hand, we could restore binding to BAM1 replacing the N-terminal of IDA by the one of CLE9

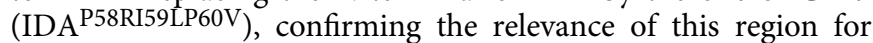
specific peptide-receptor recognition between CLE9 and BAM1 (Fig. 3a and Supplementary Fig. 10). 
a

C

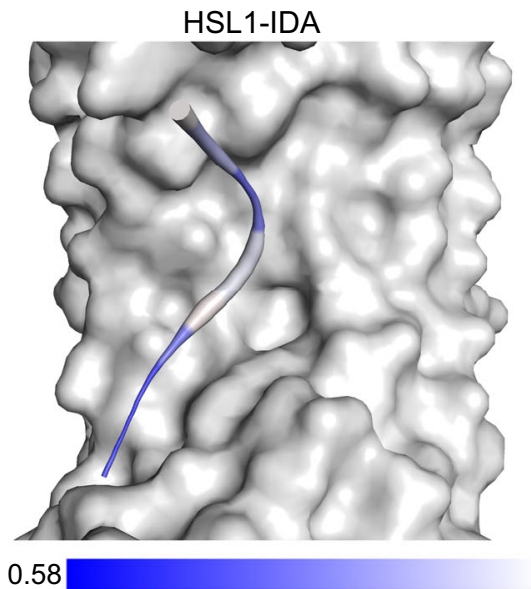

b

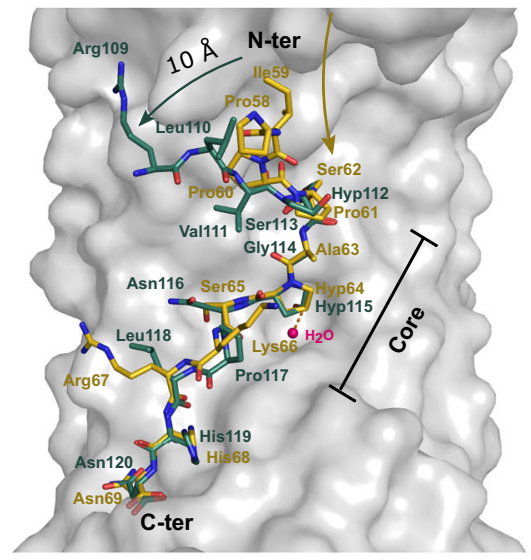

HSL1-CLE9

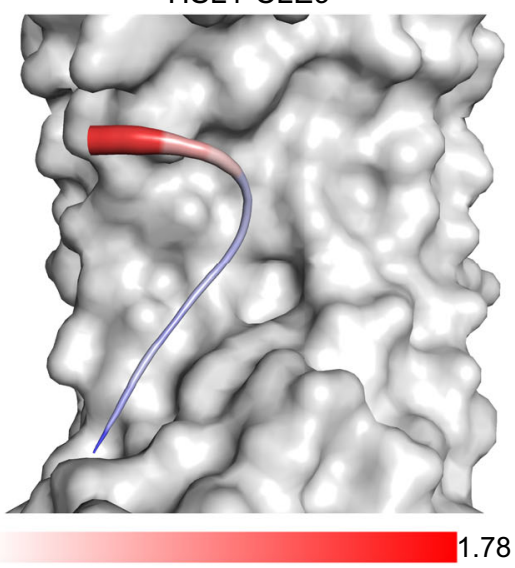

Normalized B-factors

d

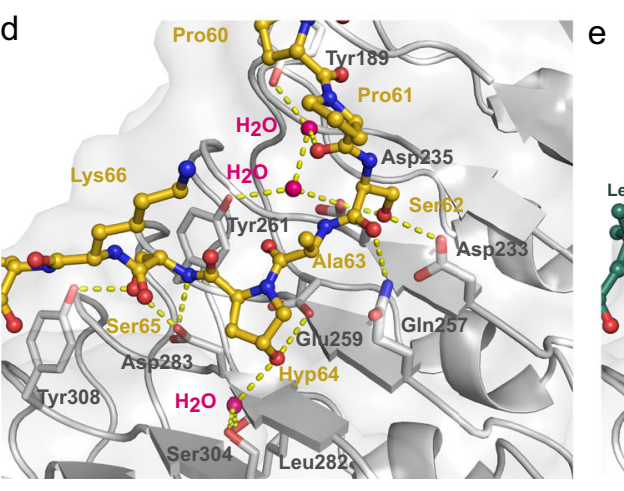

f

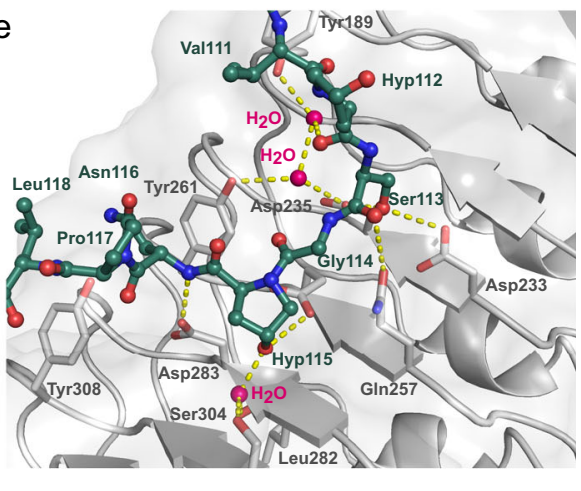

\begin{tabular}{|c|c|c|c|}
\hline Ligand (syringe) & Protein (cell) & $\mathrm{K}_{d}(\mathrm{nM})$ & $\Delta \mathrm{H}(\mathrm{kcal} / \mathrm{mol})$ \\
\hline IDA ${ }^{\text {Hyp64P }}$ & HSL1 & n.d. & n.d. \\
\hline IDA ${ }^{\text {K66AR67AH68A }}$ & HSL1 & $5910 \pm 3940$ & $0 \quad-9 \pm 2$ \\
\hline CLE9 $9^{\mathrm{N} 116 \mathrm{~S}}$ & HSL1 & $7150 \pm 2800$ & $0-18 \pm 7$ \\
\hline SERK1 & HSL1 + IDA ${ }^{\text {Hyp64P }}$ & n.d. & n.d. \\
\hline SERK1 & HSL1 + IDA ${ }^{\text {K66AR67AH68A }}$ & A $638 \pm 101$ & $-26 . \pm 8.5$ \\
\hline SERK1 & HSL1+ CLE9 ${ }^{\mathrm{N} 116 \mathrm{~S}}$ & $170 \pm 8$ & -11 \\
\hline
\end{tabular}

We next analyzed the contribution of the CLE9 central hydroxyproline to BAM1 interaction. Replacing Hyp in positions 4 and 7 by Pro in CLE9 (CLE9Hyp112PHyp115P) did not impair binding to BAM1 ( $\sim 5 \mathrm{nM}$ and $100 \mathrm{nM}$ ) (Fig. $3 \mathrm{a}$ and Supplementary Fig. 10). Similar to HSL1 vs CLE9, we did not detect interaction between the receptor BAM1 and IDA, suggesting that both receptors discriminate between their bona-fide peptides and other dodecamer peptide families (Fig. 3a and Supplementary Fig. 10). The LRR-RKs HSL1 and BAM1 present structurally divergent ligand binding sites that allow for the selection of compatible signaling peptides. High-affinity recognition between HSL1 and IDA peptides happens through their core regions, whereas BAM1 uses its $\mathrm{N}$-terminal binding site to precisely recognize CLE peptides (Fig. 3b). 


\begin{abstract}
Fig. 2 HSL1 discriminates between IDA/IDLs and the CLE9 peptide via the recognition of specific structural features in the N-terminal and core peptide regions. a IDA/IDL peptides bind to the HSL1 binding groove in a fully extended conformation. Structural superimposition of IDA (yellow bond representation), IDL1 (blue), IDL2 (green), and IDL3 (pink) in the HSL1 binding canyon (light gray). The conserved central hydroxyproline is depicted together with the crystallographic water molecule that connects it to the receptor. $\mathbf{b}$ CLE9 falls out of the HSL1 binding pocket. Close view of the structural superimposition of CLE9 (green) and IDA (yellow) in bond representation bound to the HSL1 ligand groove. The yellow arrow indicates the direction of the natural binding canyon followed by IDA (yellow), whereas the green arrow highlights the displacement (10 $\AA$ ) of the N-terminal of CLE9 (green) with respect to the HSL1 binding surface. c Temperature factor analysis of IDA and CLE9 peptides bound to HSL1 reveals a high atomic displacement parameter for the N-terminal region of CLE9 compared to IDA. Peptides are colored according to the scale of normalized B-factor values (ranging from 0.58 to 1.78 , bottom). Normalization was made using the $\mathrm{C} \alpha \mathrm{B}$-factor of the complexes as follows $\mathrm{Bi}=\mathrm{Bi} / \sqrt{ }\left(\Sigma \mathrm{Bi}^{2} / n\right)$. The surface of the HSL1 receptor is depicted in gray. d The core region of IDA/IDL peptides is specifically recognized by the receptor HSL1 through a highly coordinated network of hydrogen bonds. e CLE9 is missing a key Ser residue in position Asn116 for anchoring the peptide to the HSL1 receptor. Close up view of the core region of CLE9 (green bond representation) in complex with HSL1 (light gray). Hydrogen bonds are depicted in yellow, and waters are shown as bright pink spheres. $\mathbf{f}$ Binding analysis of IDA Hyp64P, IDA K66AR67AH68A, and CLE9N116S mutants vs. HSLI and SERK1. ITC table summaries. $K_{d}$ dissociation constant, $\mathrm{N}$ stoichiometry $(n=1$ for a 1:1 interaction). The values indicated in the table are the mean \pm SD of at least two independent experiments. $\mathbf{g}$ IDA requires the Hyp64 and its $\mathrm{C}$-terminal region for bioactivity. Abscission complementation assays of ida mutant with wild-type IDA and the IDA variants Pro64 to Gly and the triple mutant Lys66, Arg67, and H68A to Ala, driven by its endogenous promoter. A minimum of two independent lines were analyzed for floral abscission phenotype.
\end{abstract}

The above results prompted us to investigate whether HSL1 would sense IDA in vivo. To test this, we drove the expression of HSL1 in the abscission zone (AZ) using the HAESA promoter and we analyzed the recovery of floral shedding in the double mutant hae hsl2 (Fig. 4a). Expressing HAESA under the HSL1 promoter failed to complement de hae hsl2 mutant, suggesting that HSL1 is not typically expressed in AZ (Fig. 4a). However, the expression of HSL1 under the HAESA promoter fully restored the floral shedding phenotype, indicating that HSL1 can recognize IDA in physiological conditions and mimic the receptor HAESA, triggering the floral abscission signaling pathway (Fig, 4a-b).

CLE9 and HSL1 have been reported to be expressed in leaf epidermis and to negatively regulate the proliferation of stomatal lineage cells ${ }^{21,22}$. Thus, we examined if BAM1 receptor would also be expressed in this tissue. $p B A M 1:: 3 x N L S:: Y F P$ reporter lines confirmed that BAM1 is also expressed in the leaf epidermal tissue along with CLE9 (Fig. 5a). Expression of IDL4 has been reported in the guard cells (GC) of young seedlings ${ }^{39}$. Generation of pIDL4::3xNLS:mScarlet confirmed its expression in GCs, and revealed that IDL4 is also expressed in pavement and meristemoid mother cells in leaf epidermis (Fig. 5a). Next, we investigated the effect of loss-of-function hsll and the double mutant bam1 bam 2 in epidermal cell division and stomata development in cotyledons. We analyzed the double mutant bam1-4 bam2-426 in Col-0 background that displays a characteristic short root phenotype observed in other bam1 bam2 combinations $^{28}$ (Supplementary Fig. 11). Interestingly, the double mutant bam1 bam 2 consistently showed an increased number of cell divisions, resulting in a higher number of total cells, including stomata and non-guard cells when compared to wild-type cotyledons (Fig. 5b-d and Supplementary Fig. 11). These observations, together with our structural and biochemical analysis, suggest that BAM1/2 regulates epidermal cell division homeostasis via the sensing of CLE peptides expressed in leaves. On the other hand, hsl1 mutant showed a reduced number of total amount of cells, mainly in stomata number (Fig. 5b-d and Supplementary Fig. 11), with enlarged pavement cells potentially compensating for the shortage in leaf cell number ${ }^{40}$ (Fig. 5d). These results indicate that epidermal cell development is guided by several layers of regulation mediated by different LRR-RKs and peptide hormones.

\section{Discussion}

The organization of receptors and their cognate peptide ligands in large gene families, renders identification of bona-fide receptor-ligand pairs in plant development challenging.
Our work reveals that HSL1 is a receptor for IDA/IDL signaling peptides. By comparing the binding mode between IDA/ IDLs and the sequence-related but functionally distinct CLE9 peptide, we uncover how their cognate plant LRR-RKs discriminate between the different signaling peptide families (Fig. 3b $)^{41}$. Our structural, quantitative biochemistry, and genetic data reveal that IDA/IDL peptides use their conserved $\mathrm{N}$-terminus and core regions (S-[G/A]-Hyp-S motif) to fully occupy the ligand groove of HSL1 and sequence-related HAESA receptors (Fig. 1e, Fig. 2a,d and Fig. 3b, and Supplementary Fig. 6). In contrast, structural analysis of the HSL1-CLE9-SERK1 complex reveals that CLE9 is only partially recognized by HSL1, rationalizing the reduced binding affinities when compared to IDA/IDLs (20-fold reduction) (Fig. 1a, b and Fig. 2b, c, e). Our ligand binding assays are in agreement with the previously reported binding affinities for HSL1 vs. CLE9 $(38 \mu \mathrm{M})$, and for the association with the co-receptor SERK1 $(1.5 \mu \mathrm{M})^{21}$

Structural superimposition of the CLE-receptor $\mathrm{PXY}^{25}$ and HSL1 highlights that HAE-type and CLE-sensing receptors have evolved different peptide-binding surfaces in their LRR domain: HSL1 features a set of bulky amino acids in the N-terminal part of the binding surface, incompatible with specific CLE peptide perception. In contrast, CLE-sensing receptors contain a conserved core pocket composed of bulky residues that prevent the formation of the extended hydrogen-bonding network that we show is critical for IDA/IDL recognition (Fig. 2d, Supplementary Fig. 7, Supplementary Fig. 9).

Consistent with our previous work on HAESA ${ }^{4}$, the HSL1IDA/IDL structures and genetic complementation assays show that the central hydroxyproline in IDA/IDLs is buried in the HSL1 peptide-binding groove and essential for receptor-peptide recognition and bioactivity (Fig. 2 a-d, f, g). Together, our data support that HSL1 shares a peptide recognition mechanism with other HAE-type receptors. However, HSL1 displays an extended hydrogen-bonding network in its core ligand interaction surface (Fig. 2d and Supplementary Fig. 12), accounting for the higher binding affinity to IDA/IDL peptides when compared to HAESA (Fig. 1a-d and Supplementary Fig. 2-4 and 12) ${ }^{4}$.

In contrast, CLE9 requires its first three $\mathrm{N}$-terminal residues to be specifically recognized by its cognate receptor BAM1 (Fig. 3a, b). This distinct perception mechanism is shared among other CLE peptides ${ }^{25,41}$, suggesting that CLEs may use their sequencediverse N-terminus to target specific CLE receptors (Fig. 3a, b) ${ }^{41}$.

Unlike IDA/IDLs, CLE peptides have been reported to carry hydroxyprolines that can be further glycosylated. This additional post-translational modification can strengthen receptor-ligand interaction $^{8}$. In the case of CLE9, different combinations of 
a

\begin{tabular}{|c|c|c|c|c|c|}
\hline & Ligand (syringe) & Protein $_{\text {(cell }}$ & $\mathrm{K}_{d(\mathrm{nM})}$ & $\Delta \mathrm{H}_{(\mathrm{kcal} / \mathrm{mol})}$ & $\mathrm{N}$ \\
\hline CLE9 & RLVPHypSGP Hyp NPLHN & BAM1 & $94 \pm 56$ & $-20 \pm 4$ & 1 \\
\hline CLE9 ${ }^{R 109 P}$ & PLVPHypSGPHypNPLHN & BAM1 & $91 \pm 24$ & $-26 \pm 8$ & 1 \\
\hline CLE9 ${ }^{\text {R109PL110I }}$ & PIVPHypSGP HypNPLHN & BAM1 & $129 \pm 45$ & $-27 \pm 11$ & 1 \\
\hline CLE9 ${ }^{V 111 P}$ & RLPP ${ }^{\text {Hyp }} S G P^{H y p} N P L H N$ & BAM1 & $3000 \pm 1080$ & $-19 \pm 8.3$ & 1 \\
\hline CLE9 ${ }^{\text {R109PV111P }}$ & PLPP HypSGP ${ }^{\text {Hyp NPLLHN }}$ & BAM1 & $2240 \pm 400$ & $-3.7 \pm 0.4$ & 1 \\
\hline CLE9 R109PL110IV111P & PIPP Hyp SGP Hyp NPLHN & BAM1 & n.d & n.d & 1 \\
\hline CLE9 & RLVPSGPNPLHN & BAM1 & $3 \pm 2$ & $-18.1 \pm 2$ & 1 \\
\hline IDA & PIPPSAPHyPSKRHN & BAM1 & n.d & n.d & \\
\hline IDA P58RI59LP60V & RLVPSAPHyPSKRHN & BAM1 & $980 \pm 27$ & $-15.5 \pm 0.7$ & 1 \\
\hline
\end{tabular}

b

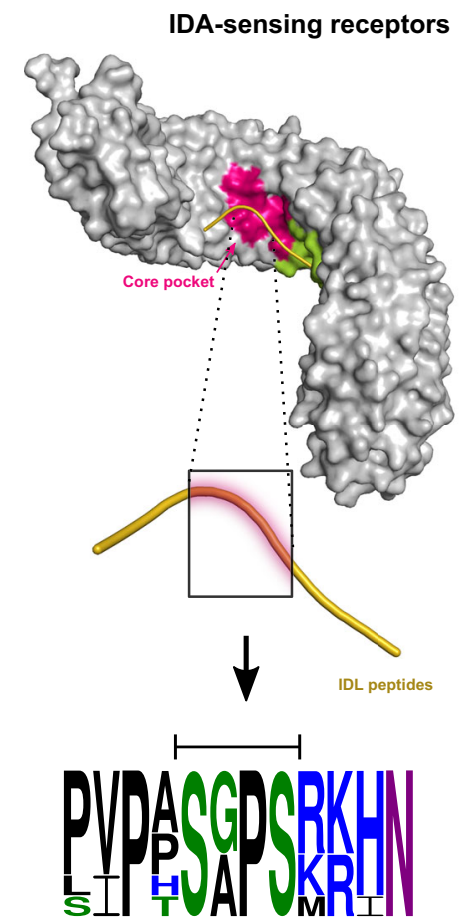

CLE-sensing receptors

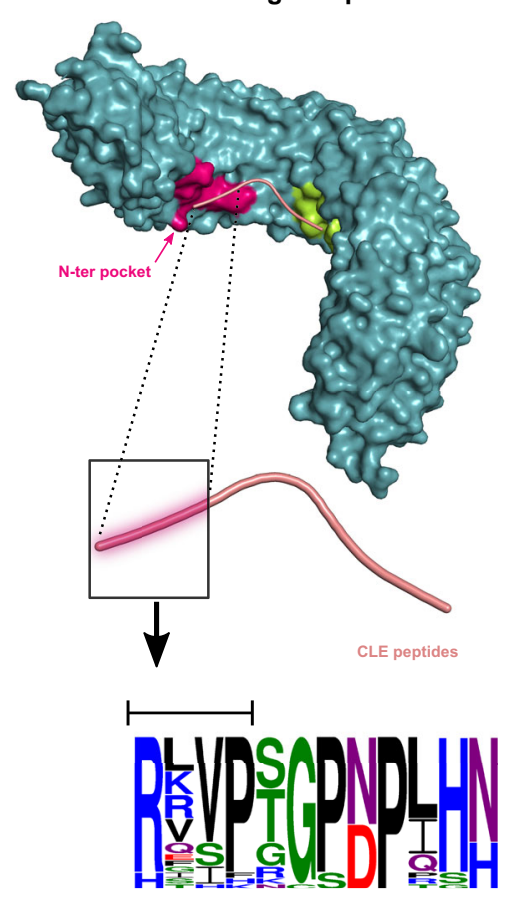

Fig. 3 The CLE9 peptide uses its $\mathbf{N}$-terminal region to specifically anchor to its cognate receptor BAM1. N-terminal engineered CLE9 peptides lose their capacity to bind the BAM1 LRR ectodomain a ITC table summaries of engineered CLE9 and IDA variants versus BAM1. $\mathrm{K}_{d}$, dissociation constant; N, stoichiometry ( $n=1$ for a 1:1 interaction). The values indicated in the table are the mean \pm SD of at least two independent experiments. $\mathbf{b}$ Representation of the specific recognition features of IDA/IDLs and CLE-like peptides by their cognate receptors. IDA/IDL peptides and IDA-like receptors are depicted in gold (cartoon) and gray (surface), respectively. CLE-like peptides and CLE-like receptors are shown in pink (cartoon) and dark cyan (surface), respectively. The receptor region highlighted in magenta depicts unique structural features for peptide recognition in each type of receptors; and illustrates the receptor region where the peptide is highly coordinated to form a high-affinity binding pair. We termed these regions "core pocket" and "N-ter pocket" for the IDAlike and CLE-like receptors, respectively. The surface depicted in light green corresponds to a common receptor architecture, with a similar peptide-binding recognition in both types of receptors. A magnification of the peptides is shown to highlight the amino acid position at the specific receptor pocket. Peptide sequence logos for each peptide family were generated through the WebLogo 3 server (http://weblogo.threeplusone.com/ ${ }^{70}$ ) using the sequence information of the IDA/IDL peptides (IDA and IDL1-6) and the mature sequence of the $27 \mathrm{~A}$. thaliana CLE peptides ${ }^{71}$. The size of the amino acid letters correlates with the residue frequency, and the color code depicts the following amino acid properties: green for polar, purple for neutral, blue for basic, red for acidic and black for hydrophobic residues.

arabinosylated peptide species have been detected in planta with no obvious contribution to receptor binding ${ }^{17}$. Our quantitative binding assays indicate that Hyp modifications in CLE9 are not required to anchor CLE9 to its receptor BAM1 (Fig. 3a). It is of note, that our structural and biochemical analysis support previous phylogenetic studies that classify IDA/IDL and CLV3/CLE peptides in two distinct gene families ${ }^{15,42}$.

This study, together with previous reports ${ }^{21,39}$, suggests a function for the LRR-RKs BAM1 and HSL1, and their cognate peptides ligands CLE9 and IDL4, respectively, in leaf epidermal development (Fig. 5a-d). CLE9 has been previously reported to act as a negative regulator of stomatal lineage proliferation through destabilization of the transcription factor SPEECHLESS ${ }^{21}$; and to signal via its cognate receptor BAM1 to control xylem file number in roots ${ }^{21}$. We find that leaf epidermal cell number is increased in bam 1 bam 2 mutants (Fig. 5b-d), suggesting an additional role for BAM1/2 in epidermal cell division homeostasis. Qian et al. did not observe an increased 
a

hae $h s / 2$

Col-0

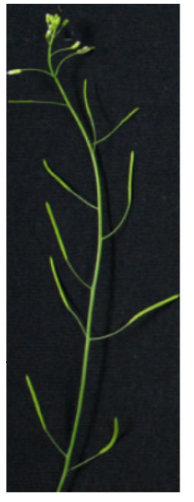

hae $h s / 2$

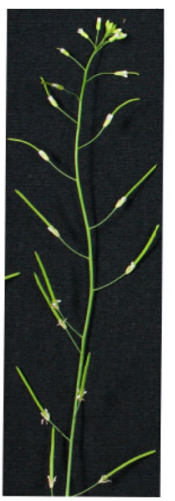

b $h s / 1$

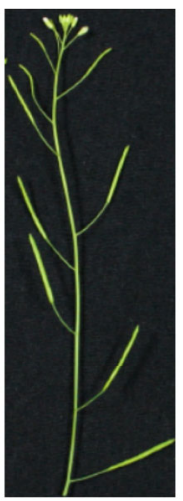

pHSL1::HAE pHAE::HSL1\#1 pHAE::HSL1 \#2
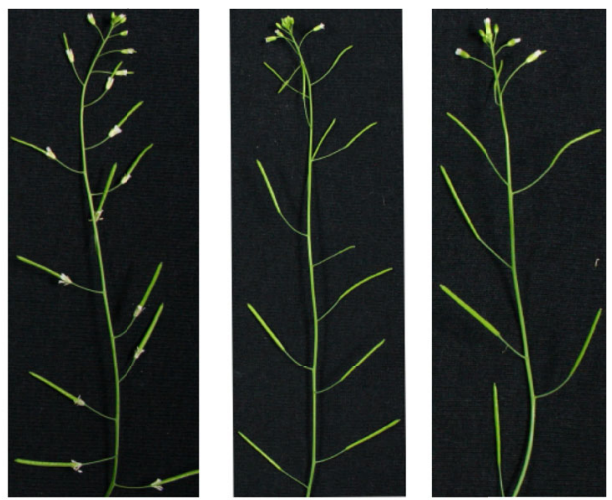
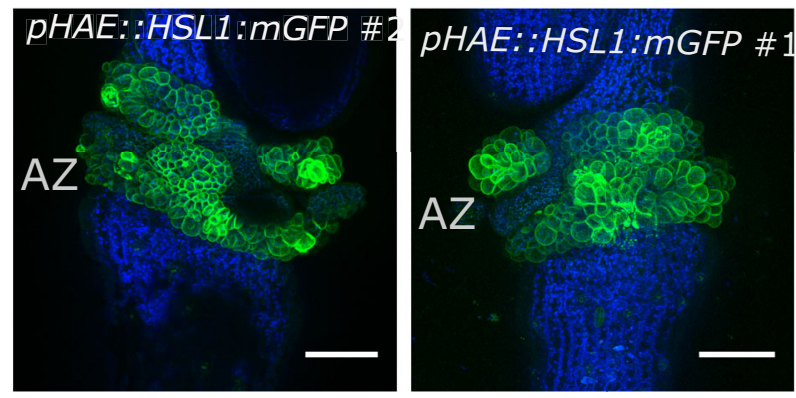

Fig. 4 The LRR-RK HSL1 can mimic HAESA, acting as a positive regulator of floral abscission. a HSL1, which is not typically expressed in abscission zone (AZ), can perceive IDA in vivo and replace the receptor HAESA in floral shedding. Abscission complementation assays of hae hs/2 double mutant expressing the receptor HSL1 under the HAESA promoter. As control, the HAESA receptor was expressed under the HSL1 promoter. A minimum of two independent lines were analyzed for floral abscission phenotype. Wilt type Col-0, and hae $h s / 2$ and hs/7 mutants were also phenotyped alongside. b Localization of HSL1 in AZ under the expression of the HAESA promoter. Confocal images of AZ of pHAESA::HSL1::mGFP lines. Scale bar = 100 um.

number of epidermal cells in the bam 1 bam 2 mutant allele used in their study. Since their allele (bam1-3 bam2-101) did not show the characteristic bamlbam2 short root phenotype (Supplementary Fig. 11) ${ }^{28}$, we speculate that it may represent a weak allele, potentially explaining the masking of the cell division phenotype ${ }^{21}$.

Our work demonstrates that $h s l 1$ has a reduced number of stomata in the leaf epidermis (Fig. 5b,d). This suggests that HSL1 has a positive regulatory role in the control of epidermal cell patterning via the perception of IDA/IDL peptides, with IDL4 being present in the tissue (Fig. $5 \mathrm{a}, \mathrm{b}-\mathrm{d})^{39}$. Thus, HSL1 and BAM1/2 may have antagonistic roles in leaf epidermal cell homeostasis, by specifically interacting with two distinct classes of signaling peptides.

An alternative scenario would be that HSL1 has evolved to sense IDA/IDLs and CLE9 with different binding affinities. For this scenario to be of in vivo relevance, higher concentrations of CLE9, in leaf epidermal tissue, would be required to efficiently compete with IDLs to bind HSL1. However, binding of both peptide families would result in the HSL1-SERK1 complex formation, triggering the same cytosolic signaling outputs ${ }^{36,43}$.

How these different receptor-ligand-co-receptor signaling complexes integrate with the well-characterized stomatal lineage and cell differentiation pathway ${ }^{44,45}$, will provide future mechanistic understanding of how different signaling inputs shape plant development.

\section{Methods}

Protein expression and purification. All genes used for protein expression in Trichoplusia ni Tnao38 cells ${ }^{46}$ were codon optimized and cloned into a modified
pFastBac vector (Geneva Biotech) providing an azurocidin ${ }^{47}$ or Drosophila BIP signal peptide ${ }^{48}$, a TEV (tobacco etch virus protease) cleavage site and a Strep9xHis tandem affinity tag at their carboxy terminus. The genes used are coding for the Arabidopsis ectodomains of HSL1 (residues 17-618, AT1G28440), HAE (residues 20-620, AT4G28490) SERK1 (residues 24-213, AT1G71830), and BAM1 (residues 20-637, AT5G65700). To perform Grating-coupled interferometry (GCI) experiments, HSL1 was fused to a non-cleavable Avi-tag 49,50 . Baculovirus generation was carried out in DH10 cells and virus amplification was done in Spodoptera frugiperda Sf9 cells. For protein expression, Trichoplusia ni Tnao38 cells were infected with HAE, HSL1, BAM1 and SERK1 virus with a multiplicity of infection (MOI) of 3 . The cells were grown 1 day at $28^{\circ} \mathrm{C}$ and two days at $22^{\circ} \mathrm{C}$ at $110 \mathrm{rpm}$. After every expression round, secretion of our proteins was detected using an anti-His-HRP conjugated antibody from Roche (Ref:11965085001) in a 1:2000 dilution. The secreted proteins were purified separately by sequential $\mathrm{Ni}^{2+}$ (HisTrap excel, GE Healthcare, equilibrated in $25 \mathrm{mM} \mathrm{KPi} \mathrm{pH7.8} \mathrm{and} 500 \mathrm{mM}$ $\mathrm{NaCl}$ ) and Strep (Strep-Tactin Superflow high-capacity, (IBA, Germany) equilibrated in $25 \mathrm{mM}$ Tris $\mathrm{pH} 8.0,250 \mathrm{mM} \mathrm{NaCl}, 1 \mathrm{mM}$ EDTA) affinity chromatography. Next, affinity tags were removed by incubating the purified proteins with recombinant His-tagged TEV protease, in a 1:50 ratio. The cleaved tag and the protease were separated from the ectodomains by a second $\mathrm{Ni}^{2+}$ affinity step. Proteins were further purified by size-exclusion chromatography on a Superdex 200 Increase 10/300 GL column (GE Healthcare) equilibrated in $20 \mathrm{mM}$ citric acid pH 5.0, $150 \mathrm{mM} \mathrm{NaCl}$. Peak fractions containing the single proteins or complexes were concentrated using Amicon Ultra concentrators (Millipore, MWCO 10,000 for SERK1 and 30,000 for HAE, HSL1, and BAM1) and used for crystallization or biochemical experiments. Proteins were analyzed for purity and structural integrity by SDS-PAGE.

Crystallization and data collection. Crystals of the isolated HSL1 ectodomain developed at $18^{\circ} \mathrm{C}$ in hanging drops (vapor diffusion) composed of $1.0 \mu \mathrm{L}$ of protein solution $(12 \mathrm{mg} / \mathrm{mL})$ and $1.0 \mu \mathrm{L}$ of the crystallization buffer $(0.2 \mathrm{M}$ ammonium sulfate, $0.1 \mathrm{M}$ citric acid $\mathrm{pH} 4.0$, 30\% w/v PEG 1000), suspended above $0.6 \mathrm{~mL}$ of crystallization buffer. For structure solution crystals were derivatized and cryoprotected by serial transfer into crystallization buffer supplemented with $20 \%$ ethylene glycol and snap frozen in liquid nitrogen. A $1.83 \AA$ native dataset was 
a
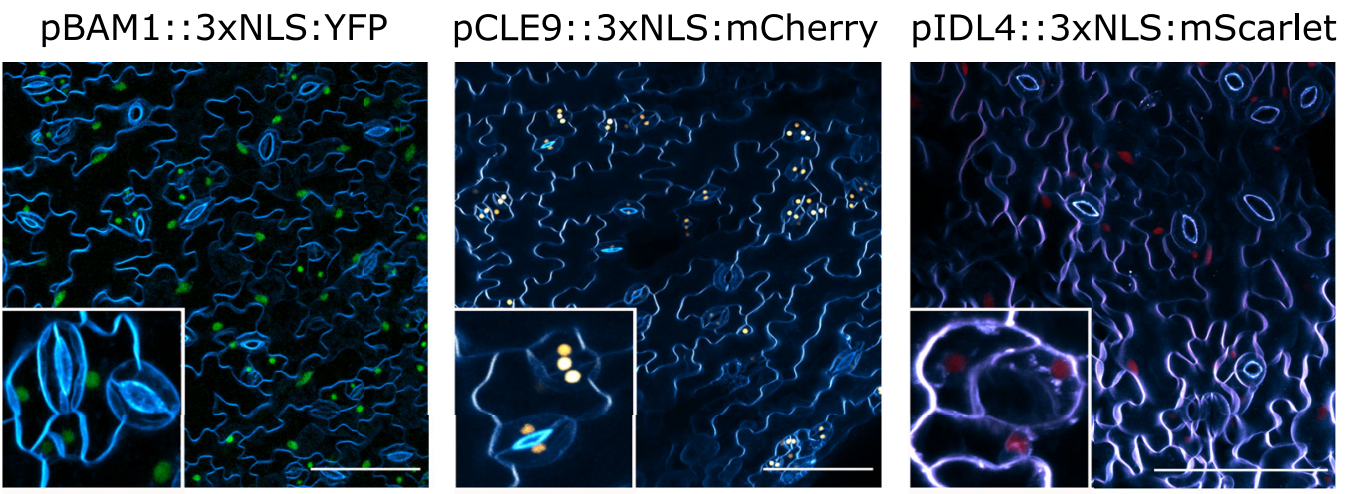

b

Total number of cells

Area $P A \cdot B \cdot D \cdot E$
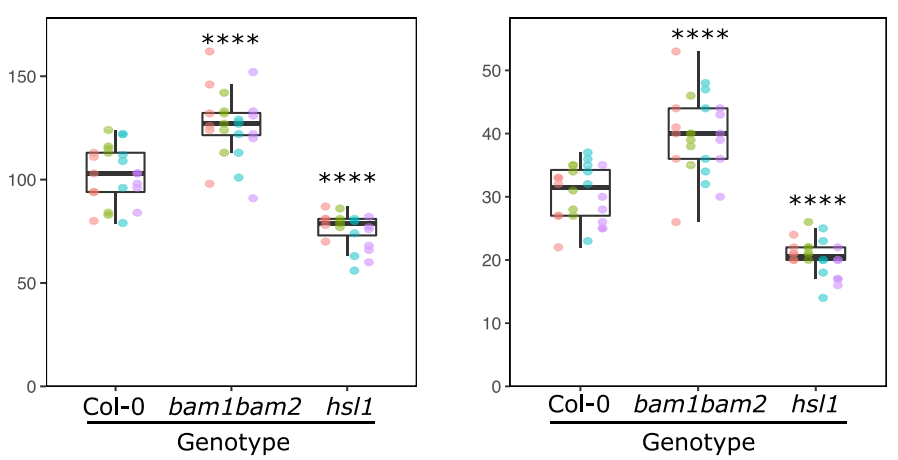

C

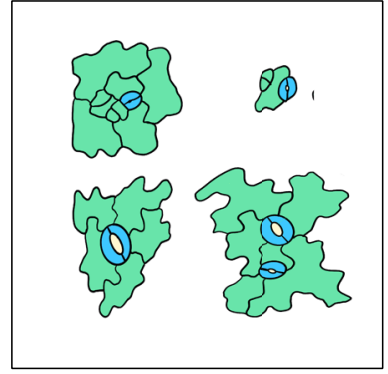

d

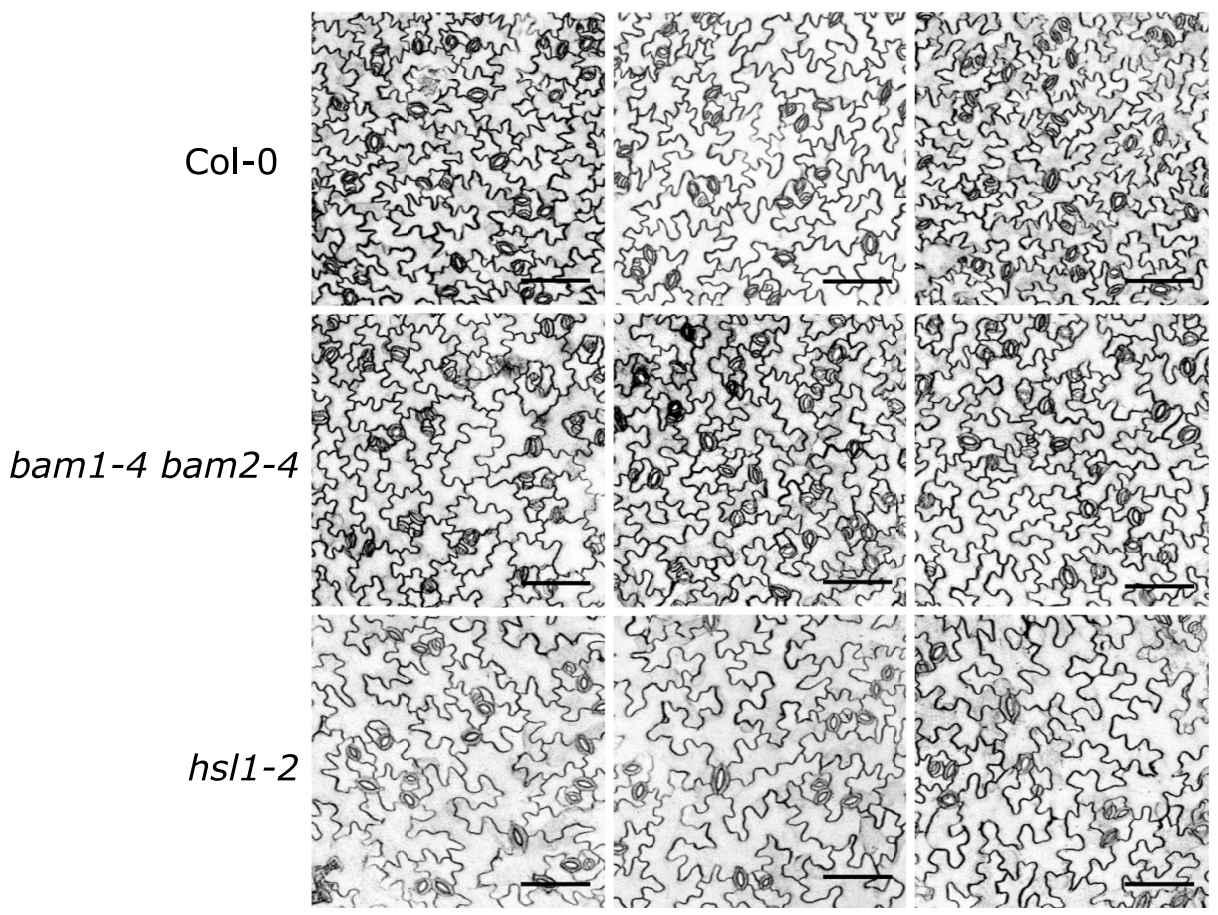

collected. Ternary complexes of HSL1 with the peptides IDA, IDL1, IDL2, IDL3, CLE9, and the protein SERK1, were obtained by mixing HSL1, SERK1 and the peptide hormones in a 1:1:1.5 molar ratio. Crystals from the different complexes also grew at $18{ }^{\circ} \mathrm{C}$ in hanging drops (vapor diffusion) composed of $1.0 \mu \mathrm{L}$ of protein solution $(15 \mathrm{mg} / \mathrm{mL})$ and $1.0 \mu \mathrm{L}$ of the crystallization buffer suspended above $0.6 \mathrm{~mL}$ of its corresponding crystallization buffer. The different complexes crystallized in the following conditions: crystals from HSL1-IDA-SERK1 complex grew in $0.2 \mathrm{M} \mathrm{K} / \mathrm{Na}$ tartrate and $20 \% \mathrm{w} / \mathrm{v}$ PEG 3350 . Crystals were cryoprotected using
$15 \%(\mathrm{v} / \mathrm{v})$ ethylene glycol and snap frozen in liquid nitrogen. Two datasets from the same crystal were merged and used for structure determination at 2.31 Å. Crystals from the HSL1-IDL1-SERK1 complex developed in $0.2 \mathrm{M}$ ammonium citrate tribasic $\mathrm{pH} 7.0$ and $20 \% \mathrm{w} / \mathrm{v}$ Polyethylene glycol 3350 Crystals were cryoprotected using $15 \%(\mathrm{v} / \mathrm{v})$ ethylene glycol and snap frozen in liquid nitrogen. Two datasets from the same crystal were merged and used for structure determination at $2.38 \AA$ resolution. In the case of HSL1-IDL2-SERK1 crystals, they grew in $0.2 \mathrm{M}$ ammonium sulfate, $0.1 \mathrm{M}$ Bis-Tris and 25\% w/v PEG 3350. Crystals were cryoprotected 
Fig. 5 The receptors HSL1 and BAM1-BAM2 impact epidermal cell patterning via signaling of two distinct peptide families. a BAM1, the peptide CLE9 and IDL4 express in the same or neighboring cell types in epidermal tissue. Expression pattern of pIDL4::3xNLS:::mScarlet, pCLE9::3xNLS::mCherry and pBAM1::3xNLS::YFP in the abaxial side of 5-day-old cotyledons. Scale bar $=100 \mu \mathrm{m} \mathbf{b}$ BAM1/2 and HSL1 regulate epidermal cell development. Effects of the double mutant bam1-4 bam2-4 and hs/1-2 on the number of stomata and total number of cells in cotyledons of 10-day-old seedlings. Box plots representing the different total number of cells and stomata of Col-0 vs bam1-4 bam2-4 and hs/1-2. ${ }^{\star} p<0.05,{ }^{\star \star} p<0.01,{ }^{\star \star \star} p<0.001$ and ${ }^{\star \star \star \star} p<0.0001$ by two-sided mixed effect model with a Poisson link function and area as a random factor. The different areas counted per cotyledon are depicted in different colors. $\mathrm{n}=2457,3028,1822$ cells were counted over 6 independent cotyledons for Col-0, bam1-4 bam2-4 and hs/7-2, respectively. The centerline of the box plots represents the median value (50th percentile), while the box contains the 25th to 75th percentiles of the dataset. The black whiskers mark the 5th and 95th percentiles, and values beyond these upper and lower bounds are considered outliers. c Schematic representation of epidermal cells counted in cotyledons in b. Young and well-defined stomata are depicted in blue. Non-guard cells (NGCs) are depicted in green, including pavement cells and stomata lineage ground cells (SLGCs). d Representative confocal images of hs1-2, bam1-4 bam2-4, and wild-type Col-0 cotyledons analyzed in the experiment shown in (b). Scale bar $=100 \mu \mathrm{m}$.

$20 \%$ (vol/vol) ethylene glycol. A native dataset to $2.20 \AA$ resolution was collected. Crystals of the complex HSL1-IDL3-SERK1, developed in $0.2 \mathrm{M} \mathrm{MgCl}_{2}, 0.1 \mathrm{M}$ HEPES pH 7.5 and 25\% PEG 3350, and crystals were cryoprotected in $15 \%(\mathrm{v} / \mathrm{v})$ ethylene glycol prior to flash freezing in liquid nitrogen. A native dataset to $2.70 \AA$ resolution was collected. The complex HSL1-CLE9-SERK1 crystallized in $0.2 \mathrm{M} \mathrm{K} /$ $\mathrm{Na}$ tartrate, $20 \% \mathrm{w} / \mathrm{v}$ PEG 3350. Crystals were cryoprotected in $25 \%(\mathrm{v} / \mathrm{v})$ ethylene glycol. A dataset to $2.87 \AA$ resolution was collected. Data from all the crystals were collected at beam-line PXIII at the Swiss Light Source (SLS), Villigen, CH.

Structure determination and refinement. Diffraction intensities for HSL1 apo and for the different peptide complexes were integrated and scaled with DIALS using xia $2^{51}$ and AIMLESS ${ }^{52}$, respectively. The specified lattice symmetry for each crystal is indicated in Supplementary Table 1. The structure of HSL1 was determined by molecular replacement using the program PHASER, implemented in the Phenix Mrage pipeline ${ }^{53}$. Search models were selected using the program HHPRED $^{54}$ and tested iteratively in the Mrage pipeline. The solution was based on LRR ectodomain of HAESA (PDB: 5IXO) ${ }^{4}$ and gave the asymmetric unit. Molecular replacement solutions for the IDA/IDLs and CLE9 complexes were found with Phaser-MR using the crystal structure of HAESA-IDA-SERK1 (PDB ID: 5IYX) as search template. Translational non-crystallographic symmetry (tNCS) was detected in the IDL3 crystal using Xtriage ${ }^{55,56}$ and a molecular replacement solution was found taking tNCS into account for this dataset. The models were manually adjusted to improve the fit to likelihood weighted electron density maps using $\operatorname{Coot}^{57}$. Solvent molecules were added where they were supported by both chemistry and geometry. Crystallographic refinement was performed with Refmac $5^{58}$ using NCS for all the structures. TLS refinement was applied for the IDL2 complex. The effect of tNCS on the R factors of the IDL3 complex is reflected in the refinement statistics, Supplementary Table 1 . The quality and stereochemistry of the model were evaluated using Molprobity ${ }^{59}$ and the wwPDB Validation Server (https://validate-rcsb-2.wwpdb.org/).

Homology modeling and peptide docking. BAM1 LRR domain (residues 21 to 640) was used to build a homology model through the Swiss-Model homologymodeling server, using as a template the crystal structure of the receptor PXY in complex with the peptide CLE41 ${ }^{25}$ (PDB ID 5GRQ, sequence identity $42 \%$, coverage $92 \%$ ). The docking was performed using three starting peptide orientations based on CLE41 in PXY, and CLE9 and IDA in HSL1. Final peptide-receptor docking/refinement was performed using high-resolution modeling through the Rosetta FlexPepDock tool ${ }^{38}$, total energy score of -428.085 and a RMSD of 0.760 .

Analytical size-exclusion (SEC) chromatography. Analytical SEC experiments were performed using a Superdex 200 Increase 10/300 GL column (GE). The columns were pre-equilibrated in $20 \mathrm{mM}$ citric acid pH 5, $100 \mathrm{mM} \mathrm{NaCl} .200 \mu \mathrm{g}$ of HSL1 and the different mutant variants were incubated with SERK1 in the absence or presence of indicated peptides in a 1:1:1.5 molar ratio. Similar protein amounts were used for BAM1 SEC analysis. A non-contributing N-terminal Tyr residue was added to some of the IDA/IDL peptides to allow for peptide quantification by UV absorbance. Protein mixes were injected sequentially onto the column and eluted at $0.5 \mathrm{~mL} / \mathrm{min}$. Ultraviolet absorbance (UV) at $280 \mathrm{~nm}$ was used to monitor the elution of the proteins. The peak fractions were analyzed by SDS-PAGE followed by Coomassie blue staining.

Isothermal titration calorimetry (ITC). Experiments were performed at $25^{\circ} \mathrm{C}$ using a MicroCal PEAQ-ITC (Malvern Instruments) with a $200 \mu \mathrm{L}$ standard cell and a $40 \mu \mathrm{L}$ titration syringe. HSL1, BAM1, and SERK1 proteins were gel-filtrated into the ITC buffer (20 mM sodium citrate $\mathrm{pH} 5.0,150 \mathrm{mM} \mathrm{NaCl})$. Molar protein concentrations for HSL1, BAM1, and SERK1 were calculated using their molar extinction coefficient and a molecular weight of 74,896 and 27,551 Da, respectively as previously determined ${ }^{4}$. A typical experiment consisted of injecting $2 \mu \mathrm{L}$ of a range between 75 and $600 \mu \mathrm{M}$ solution of ligand into 10 to $30 \mu \mathrm{M}$ HAE, HSL1, or BAM1 solution in the cell at $150 \mathrm{~s}$ intervals and $500 \mathrm{rpm}$ stirring speed. The SERK1 vs HAE/HSL1-peptide experiments were performed by titrating $100 \mu \mathrm{M}$ SERK1 in the cell, using the same injection pattern. ITC data were corrected for the heat of dilution by subtracting the mixing enthalpies for titrant solution injections into protein-free ITC buffer. Experiments were done in duplicates or triplicates, otherwise specified, and data were analyzed using the MicroCal PEAQ-ITC Analysis Software provided by the manufacturer. All ITC runs used for data analysis have an $\mathrm{N}$ ranging from 0.7 to 1.3. The $\mathrm{N}$ values were fitted to 1 in the analysis. For binding experiments, a Tyr $(\mathrm{Y})$ residue was introduced in some IDA/IDL peptides to facilitate concentration measurements. We tested and confirmed that the addition of this extra residue in the N-terminal does not affect IDA/IDLs binding capacity to HAE-type receptors ${ }^{4}$ (Supplementary Table 2).

Protein Biotinylation. $25 \mu \mathrm{M}$ of HSLl were biotinylated with the biotin ligase $\operatorname{BirA}^{60}(2 \mu \mathrm{M})$ for $1 \mathrm{~h}$ at $30^{\circ} \mathrm{C}$, in a volume of $200 \mu \mathrm{l}$. The buffer used in the reaction was: $25 \mathrm{mM}$ Tris $\mathrm{pH} 8,150 \mathrm{mM} \mathrm{NaCl}, 5 \mathrm{mM} \mathrm{MgCl}$, $2 \mathrm{mM}$ 2-Mercaptoethanol, $0.15 \mathrm{mM}$ Biotin, $2 \mathrm{mM}$ ATP. Biotinylated proteins were purified by sizeexclusion chromatography in $20 \mathrm{mM}$ citric acid pH5, $150 \mathrm{mM} \mathrm{NaCl}$ and subsequently used in GCI experiments.

Grating-coupled interferometry binding assays. GCI experiments were performed with the Creoptix WAVE system (Creoptix AG, Switzerland) using 4PCP WAVE chips (thin quasiplanar polycarboxylate surface; Creoptix, Switzerland). Chips were first conditioned with borate buffer ( $100 \mathrm{mM}$ sodium borate $\mathrm{pH} 9.0$, $1 \mathrm{M} \mathrm{NaCl}$; Xantec, Germany). Chips were activated with 1:1 mix of $400 \mathrm{mM} \mathrm{N}$-(3dimethylaminopropyl)- $N^{\prime}$-ethylcarbodiimide hydrochloride and $100 \mathrm{mM}$ N-hydroxysuccinimide (Xantec, Germany). Streptavidin $(50 \mu \mathrm{g} / \mathrm{ml}$; Sigma, Germany) in $10 \mathrm{mM}$ sodium acetate pH 5.0 (Sigma, Germany) was immobilized on the chip surface until saturation was reached, followed by passivation of the surface with BSA ( $50 \mu \mathrm{g} / \mathrm{ml}$; Sigma, Germany) in $10 \mathrm{mM}$ sodium acetate $\mathrm{pH} 5.0$, and a final quenching step with $1 \mathrm{M}$ ethanolamine pH 8.0 (Xantec, Germany). Then, biotinylated HSL1 (ligand) $(80-100 \mu \mathrm{g} / \mathrm{ml})$ was captured on the streptavidin surface until the desired density was reached. Normal kinetic analysis were performed to measure the binding of IDL peptides (analyte) to HSL1. Experiments were performed at $25^{\circ} \mathrm{C}$ with a $1: 2$ dilution series from a maximum concentration of $5-50 \mu \mathrm{M}$ peptide, in $20 \mathrm{mM}$ citrate $\mathrm{pH} 5,250 \mathrm{mM} \mathrm{NaCl}, 0.005 \%$ Tween- $20 \mathrm{v} / \mathrm{v}$. To analyze the interaction kinetics of the co-receptor SERK1, $2 \mu \mathrm{M}$ of the protein was used as a higher dilution with running buffer containing $5 \mu \mathrm{M}$ of the IDL peptides being tested. Blank injections were used for double referencing and a dimethylsulfoxide (DMSO) calibration curve for bulk correction. Analysis and correction of the obtained data were performed using the Creoptix WAVE control software (correction applied: $\mathrm{X}$ and $\mathrm{Y}$ offset; DMSO calibration; double referencing). Oneto-one binding model was used for both experiments.

Plant material and generation of transgenic lines. The genotypes used in this study: hae hsl2 ${ }^{39}$, bam1-4 bam2-4 ${ }^{26}$, ida-2 (SALK_133209) 11, and hsl1-2 (SAIL_563_E08) were in Columbia (Col-0) background, used as wild-type control. Homozygosity was verified by PCR using the primers in Supplementary Table 3. Seed sterilization was done by using a vapor phase with $\mathrm{HCl}$ to a final concentration of $2 \%$ and bleach for 2.5 hrs. Plants were plated on $1 / 2$ MS (Murashige \& Skoog) media with $1 \%$ plant agar and $\mathrm{pH} 5.8$, vernalised at $4{ }^{\circ} \mathrm{C}$ for 4 days and grown vertically under long-day conditions $\left(16 \mathrm{~h}\right.$ light with $23^{\circ} \mathrm{C}$ and $8 \mathrm{~h}$ dark with $21{ }^{\circ} \mathrm{C}$ ). For phenotyping, plants were grown at $22^{\circ} \mathrm{C}$ with $16 \mathrm{~h}$ light and $8 \mathrm{~h}$ dark. For the generation of transgenic lines, pGGZ003 final destination vector (Addgene ID: 48869) was used for GreenGate method ${ }^{61}$. When the removal of the BsaI restriction site was not possible the multisite Gateway technology (ThermoFisher Scientific, MA, USA) was used. Promoters were amplified from Arabidopsis thaliana (Col-0 ecotype) genomic DNA and the genes coding sequences were cloned from Arabidopsis cDNA: HAESA (AT4G28490), HSL1 (AT1G28440), BAM1 (AT5G65700), IDA (AT1G68765), IDL4 (AT3G18715) and CLE9 (AT1G26600). Plasmids were built using the Greengate Cloning system ${ }^{61}$. Structure-based mutations were introduced in the gene sequence by site-directed 
mutagenesis ${ }^{62}$. All transgenic lines were generated using the floral dip $\operatorname{method}^{63}$ with the Agrobacterium tumefaciens strain GV3101 or ASE (pSOUP $\left.{ }^{+}\right)$.

RNA analyses. Plants were grown on $1 / 2$ Murashige and Skoog (MS) plates with $1 \%$ plant agar. After 5 days, $100 \mathrm{mg}$ of plant tissue was collected and frozen in liquid nitrogen. Total RNA was extracted using a RNeasy plant mini kit (Qiagen, Valencia, CA), and the reverse transcription was done using a SuperScript IV Reverse Transcriptase (ThermoFisher Scientific, MA, USA). RT-qPCR amplifications and measurements were performed using a QuantStudio 3 Real Time PCRSystem by ThermoFisher Scientific. RT-qPCR amplifications were monitored using qPCR Brilliant II SYBR Mix (Agilent). The $2-\Delta \Delta$ CT (or comparative CT) method ${ }^{64}$ was used to calculate the relative quantification of gene expression, while ACTIN2 gene was used as a housekeeping gene. All the specific primers used for detection and amplification are listed in Supplementary Table 3. The data were collected from three independent technical experiments.

Transient protein expression in tobacco leaves. The transient expression experiments were done in three weeks old Nicotiana benthamiana plants. Agrobacterium tumefaciens cultures were grown in $\mathrm{LB}$ media at $28^{\circ} \mathrm{C}$ overnight. The induction mixture contained $200 \mu \mathrm{L}$ of the Agrobacterium culture (OD 0.1) and $200 \mu \mathrm{M}$ of acetosyringone in $5 \mathrm{~mL}$ of fresh infiltration media (50 mM MES, $2 \mathrm{mM}$ $\mathrm{NaH}_{2} \mathrm{PO}_{4}, 0,5 \%$ (w/v) saccharose, $\mathrm{pH} 5.6$, salt mixture containing: $\mathrm{NH}_{4} \mathrm{Cl}, \mathrm{MgSO}_{4}$, $\mathrm{KCl}, \mathrm{CaCl}_{2}, \mathrm{FeSO}_{4}$ ). The mix was let on a shaker for $6-8 \mathrm{hrs}$, at $28^{\circ} \mathrm{C}$ until reaching OD 0.2-0.3. For co-infiltration of two constructs, infiltration media with Agrobacterium harboring the desired constructs were mixed in a $1: 1 \mathrm{v} / \mathrm{v}$ ratio. The infiltrated plant material was imaged and collected after 2 days post infiltration. Leaves were cut and flash frozen in liquid nitrogen. HAESA wild-type and mutant ectodomains were tested for proper plasma membrane localization in transient expression driven by $35 \mathrm{~S}$ promoter ${ }^{65}$.

Protein localization in tobacco. Transient expression of constructs containing p35S::HAE:mVenus and mutants were imaged on a Leica SP8 microscope. The excitation and emission wavelengths used were $514 \mathrm{~nm}$ and $525-550 \mathrm{~nm}$, respectively. For the plasma membrane marker FM4-64 (ThermoFisher Scientific) the excitation wavelength was $515 \mathrm{~nm}$ and the emission was $640 \mathrm{~nm}$.

Gene expression in Arabidopsis. For protein expression pattern and localization in Arabidopsis stable lines, the following settings were used to obtain specific fluorescence signals: EGFP-ex: $470 \mathrm{~nm} / \mathrm{em}$ : $490-515 \mathrm{~nm}$, YFP or mVenus-ex: $514 \mathrm{~nm} / \mathrm{em}: 520-550 \mathrm{~nm}$, mCherry- ex: $594 \mathrm{~nm} / \mathrm{em}:$ 600-650 nm. Images were adjusted using Image ${ }^{66}$

Quantification of epidermal and stomatal cells, and statistical analysis. Plants were plated on $1 / 2$ MS (Murashige \& Skoog) media with $1 \%$ plant agar and pH 5.8, vernalized at $4^{\circ} \mathrm{C}$ for 4 days and grown vertically under long-day conditions (16 h light with $23^{\circ} \mathrm{C}$ and $8 \mathrm{~h}$ dark with $21^{\circ} \mathrm{C}$ ). Experiments were replicated in the presence and absence of $1 \%$ sucrose. All the stomata data were acquired with Leica SP8 microscope. As membrane marker for defining the cell margins, plant material was stained using FM 4-64 (ThermoFisher Scientific) in vacuum conditions as described in ${ }^{67}$. Data were collected from 11 days old seedlings from the abaxial side of cotyledon's epidermal cells. In each cotyledon, 4 regions of $0.18 \mathrm{~mm}^{2}$ were defined (A, B, D, and E), two on the left side of main nervure and two on the opposite side. These regions were used as sub-sampling in statistical analysis. All the cells, classified as stomata and non-guard cells (NGCs), were counted with the Fiji software ${ }^{66}$. For each genotype, 6 independent seedlings were used and an average of 400 cells/cotyledon for Col-0, 500 cells/cotyledon for bam 1 bam 2 and 300 cell/ cotyledon for $h s l 1$ were counted in total, in the the four regions per plant. Statistical analyses of the data were performed using a mixed-effect model with a Poisson link function and region as sub-sampling random factor for multiple, independent count endpoints in R (version 4.03). Experiment reproducibility by means of a second study was assessed using a reverse Bayesian approach ${ }^{67}$ with prior-predictive tail probabilities to define reproducibility success. The method provides a quantitative measure for replication success known as the skeptical p-value $\left(p^{\text {skeptical }}\right)^{68,69}$. $p^{\text {skeptical }}$ values of $9.6 \mathrm{e}-07,6.2 \mathrm{e}-06$ and $4.17 \mathrm{e}-05$ were calculated for the mutant bam1 bam 2 for total amount of cells, NGC and stomata, respectively. A similar reproducibility study was done for the $h s l 1$ mutant with $p^{\text {sceptical }}$ values of $6.6 \mathrm{e}-04$ for total number of cells, 0.015 for NGCs and 2.1e-04 for stomata. These values for both mutants indicate that these results are reproducible.

Reporting summary. Further information on research design is available in the Nature Research Reporting Summary linked to this article.

\section{Data availability}

The raw data supporting the findings of this paper are available in the provided Source data file. Materials from this paper are available through the corresponding author upon request. The crystal structures analyzed in this paper are deposited in the Protein data bank with PDB IDs: apo-HSL1 (7ODK), HSL1-IDA-SERK1 (7ODV), HSL1-IDL1-
SERK1 (7OGO), HSL1-IDL2-SERK1 (7OGQ), HSL1-IDL3-SERK1 (7OGZ), HSL1 CLE9-SERK1 (7OGU). Source data are provided with this paper.

Received: 12 May 2021; Accepted: 1 February 2022;

Published online: 15 February 2022

\section{References}

1. Matsubayashi, Y. Posttranslationally modified small-peptide signals in plants. Annu. Rev. Plant Biol. 65, 385-413 (2014).

2. Hohmann, U., Lau, K. \& Hothorn, M. The structural basis of ligand perception and signal activation by receptor kinases. Annu. Rev. Plant Biol. 68, 109-137 (2017).

3. Schardon, K. et al. Precursor processing for plant peptide hormone maturation by subtilisin-like serine proteinases. Science 354, 1594-1597 (2016).

4. Santiago, J. et al. Mechanistic insight into a peptide hormone signaling complex mediating floral organ abscission. eLife 5, e15075 (2016)

5. Song, W. et al. Signature motif-guided identification of receptors for peptide hormones essential for root meristem growth. Cell Res. 26, 674-685 (2016).

6. Okuda, S. et al. Molecular mechanism for the recognition of sequencedivergent CIF peptides by the plant receptor kinases GSO1/SGN3 and GSO2. Proc. Natl Acad. Sci. 117, 2693-2703 (2020).

7. Wang, J. et al. Allosteric receptor activation by the plant peptide hormone phytosulfokine. Nature 525, 265-268 (2015).

8. Ohyama, K., Shinohara, H., Ogawa-Ohnishi, M. \& Matsubayashi, Y. A glycopeptide regulating stem cell fate in Arabidopsis thaliana. Nat. Chem. Biol. 5, 578-580 (2009)

9. Butenko, M. A et al. INFLORESCENCE DEFICIENT IN ABSCISSION controls floral organ abscission in Arabidopsis and identifies a novel family of putative ligands in plants. Plant Cell 15, 2296-2307 (2003).

10. Butenko, M. A. et al. Tools and strategies to match peptide-ligand receptor pairs. Plant Cell 26, 1838-1847 (2014).

11. Kumpf, R. P. et al. Floral organ abscission peptide IDA and its HAE/HSL2 receptors control cell separation during lateral root emergence. Proc. Natl Acad. Sci. USA 110, 5235-5240 (2013).

12. Shi, C.-L. et al. The dynamics of root cap sloughing in Arabidopsis is regulated by peptide signalling. Nat. Plants 4, 596-604 (2018).

13. Meng, X. et al. Ligand-induced receptor-like kinase complex regulates floral organ abscission in Arabidopsis. Cell Rep. 14, 1330-1338 (2016).

14. Santiago, J., Henzler, C. \& Hothorn, M. Molecular mechanism for plant steroid receptor activation by somatic embryogenesis co-receptor kinases. Science 341, 889-892 (2013)

15. Cock, J. M. \& McCormick, S. A large family of genes that share homology withCLAVATA3. Plant Physiol. 126, 939-942 (2001).

16. Hirakawa, Y. et al. Non-cell-autonomous control of vascular stem cell fate by a CLE peptide/receptor system. Proc. Natl Acad. Sci. 105, 15208-15213 (2008).

17. Shinohara, H., Moriyama, Y., Ohyama, K. \& Matsubayashi, Y. Biochemical mapping of a ligand-binding domain within Arabidopsis BAM1 reveals diversified ligand recognition mechanisms of plant LRR-RKs. Plant J. 70, 845-854 (2012).

18. Kondo, T. et al. A plant peptide encoded by CLV3 identified by in situ MALDI-TOF MS analysis. Science 313, 845-848 (2006).

19. Shinohara, H. \& Matsubayashi, Y. Chemical synthesis of Arabidopsis CLV3 glycopeptide reveals the impact of hydroxyproline arabinosylation on peptide conformation and activity. Plant Cell Physiol. 54, 369-374 (2013).

20. Depuydt, S. et al. Suppression of Arabidopsis protophloem differentiation and root meristem growth by CLE45 requires the receptor-like kinase BAM3. Proc. Natl Acad. Sci. 110, 7074-7079 (2013).

21. Qian, P. et al. The CLE9/10 secretory peptide regulates stomatal and vascular development through distinct receptors. Nat. Plants 4, 1071-1081 (2018).

22. Vatén, A., Soyars, C. L., Tarr, P. T., Nimchuk, Z. L. \& Bergmann, D. C. Modulation of asymmetric division diversity through cytokinin and SPEECHLESS regulatory interactions in the arabidopsis stomatal lineage. Dev. Cell 47, 53-66.e5 (2018).

23. Hazak, O. et al. Perception of root-active CLE peptides requires CORYNE function in the phloem vasculature. EMBO Rep. 18, 1367-1381 (2017).

24. Ogawa, M., Shinohara, H., Sakagami, Y. \& Matsubayashi, Y. Arabidopsis CLV3 peptide directly binds CLV1 Ectodomain. Science 319, 294-294 (2008).

25. Zhang, H., Lin, X., Han, Z., Qu, L.-J. \& Chai, J. Crystal structure of PXY-TDIF complex reveals a conserved recognition mechanism among CLE peptidereceptor pairs. Cell Res. 26, 543-555 (2016). 
26. Crook, A. D. et al. BAM1/2 receptor kinase signaling drives CLE peptidemediated formative cell divisions in Arabidopsis roots. Proc. Natl Acad. Sci. 117, 32750-32756 (2020)

27. DeYoung, B. J. et al. The CLAVATA1-related BAM1, BAM2 and BAM3 receptor kinase-like proteins are required for meristem function in Arabidopsis. Plant J. 45, 1-16 (2006).

28. Fan, P. et al. The receptor-like kinases BAM1 and BAM2 are required for root xylem patterning. Proc. Natl Acad. Sci. 118, e2022547118 (2021).

29. $\mathrm{Hu}, \mathrm{C}$. et al. A group of receptor kinases are essential for CLAVATA signalling to maintain stem cell homeostasis. Nat. Plants 4, 205-211 (2018).

30. Nadeau, J. A. \& Sack, F. D. Control of stomatal distribution on the arabidopsis leaf surface. Science 296, 1697-1700 (2002).

31. Shpak, E. D., McAbee, J. M., Pillitteri, L. J. \& Torii, K. U. Stomatal patterning and differentiation by synergistic interactions of receptor kinases. Science 309, 290-293 (2005).

32. Hunt, L. \& Gray, J. E. The signaling peptide EPF2 controls asymmetric cell divisions during stomatal development. Curr. Biol. 19, 864-869 (2009).

33. Qi, X. et al. Autocrine regulation of stomatal differentiation potential by EPF1 and ERECTA-LIKE1 ligand-receptor signaling. eLife 6, e24102 (2017).

34. Hara, K. et al. Epidermal cell density is autoregulated via a secretory peptide, epidermal patterning factor 2 in Arabidopsis leaves. Plant Cell Physiol. 50, 1019-1031 (2009).

35. Meng, X. et al. Differential function of Arabidopsis SERK family receptor-like kinases in stomatal patterning. Curr. Biol. 25, 2361-2372 (2015).

36. Hohmann, U. et al. Mechanistic basis for the activation of plant membrane receptor kinases by SERK-family coreceptors. Proc. Natl Acad. Sci. 115, 3488-3493 (2018).

37. Moussu, S. et al. Structural basis for recognition of RALF peptides by LRX proteins during pollen tube growth. Proc. Natl Acad. Sci. 117, 7494-7503 (2020).

38. London, N., Raveh, B., Cohen, E., Fathi, G. \& Schueler-Furman, O. Rosetta FlexPepDock web server-high resolution modeling of peptide-protein interactions. Nucleic Acids Res. 39, W249-W253 (2011).

39. Stenvik, G.-E. et al. The EPIP Peptide of inflorescence deficient in abscission is sufficient to induce abscission in arabidopsis through the receptor-like kinases HAESA and HAESA-LIKE2. Plant Cell 20, 1805-1817 (2008).

40. Tsukaya, H. Interpretation of mutants in leaf morphology: Genetic evidence for a compensatory system in leaf morphogenesis that provides a new link between cell and organismal theories. Int. Rev. Cytol. 217, 1-39 (2002).

41. Li, Z., Chakraborty, S. \& Xu, G. Differential CLE peptide perception by plant receptors implicated from structural and functional analyses of TDIF-TDR interactions. PLoS ONE 12, e0175317 (2017).

42. Vie, A. K. et al. The IDA/IDA-LIKE and PIP/PIP-LIKE gene families in Arabidopsis: phylogenetic relationship, expression patterns, and transcriptional effect of the PIPL3 peptide. J. Exp. Bot. 66, 5351-5365 (2015).

43. Hohmann, U. et al. Constitutive activation of leucine-rich repeat receptor kinase signaling pathways by bak1-interacting receptor-like kinase 3 chimera. Plant Cell 32, 3311-3323 (2020).

44. Herrmann, A. \& Torii, K. U. Shouting out loud: signaling modules in the regulation of stomatal development. Plant Physiol. 185, 765-780 (2021).

45. Lee, L. R. \& Bergmann, D. C. The plant stomatal lineage at a glance. J. Cell Sci. 132, jcs228551 (2019).

46. Hashimoto, Y., Zhang, S., Zhang, S., Chen, Y.-R. \& Blissard, G. W. Correction: BTI-Tnao38, a new cell line derived from Trichoplusia ni, is permissive for AcMNPV infection and produces high levels of recombinant proteins. BMC Biotechnol. 12, 12 (2012).

47. Olczak, M. \& Olczak, T. Comparison of different signal peptides for protein secretion in nonlytic insect cell system. Anal. Biochem. 359, 45-53 (2006).

48. Smakowska-Luzan, E. et al. An extracellular network of Arabidopsis leucinerich repeat receptor kinases. Nature 553, 342-346 (2018).

49. Cull, M. G. \& Schatz, P. J. [26] Biotinylation of proteins in vivo and in vitro using small peptide tags. in Methods in Enzymology vol. 326, 430-440 (Elsevier, 2000)

50. Fairhead, M. \& Howarth, M. in Site-Specific Protein Labeling (eds. Gautier, A. \& Hinner, M. J) vol. 1266, 171-184 (Springer New York, 2015).

51. Winter, G. et al. DIALS: implementation and evaluation of a new integration package. Acta Crystallogr. D 74, 85-97 (2018).

52. Evans, P. R. \& Murshudov, G. N. How good are my data and what is the resolution? Acta Crystallogr. D 69, 1204-1214 (2013)

53. Bunkóczi, G. et al. Phaser.MRage: automated molecular replacement. Acta Crystallogr. D: Biol. Crystallogr 69, 2276-2286 (2013)

54. Söding, J., Biegert, A. \& Lupas, A. N. The HHpred interactive server for protein homology detection and structure prediction. Nucleic Acids Res. 33, W244-W248 (2005).

55. Adams, P. D. et al. PHENIX: a comprehensive Python-based system for macromolecular structure solution. Acta Crystallogr. D 66, 213-221 (2010).

56. Padilla, J. E. \& Yeates, T. O. A statistic for local intensity differences: robustness to anisotropy and pseudo-centering and utility for detecting twinning. Acta Crystallogr. D 59, 1124-1130 (2003).
57. Emsley, P. \& Cowtan, K. Coot: model-building tools for molecular graphics. Acta Crystallogr. D: Biol. Crystallogr 60, 2126-2132 (2004).

58. Murshudov, G. N. et al. REFMAC5 for the refinement of macromolecular crystal structures. Acta Crystallogr. D 67, 355-367 (2011).

59. Chen, V. B. et al. MolProbity: all-atom structure validation for macromolecular crystallography. Acta Crystallogr. D: Biol. Crystallogr. 66, 12-21 (2010).

60. Fairhead, M. \& Howarth, M. Site-specific biotinylation of purified proteins using BirA. Methods Mol. Biol. 1266, 171-184 (2015).

61. Lampropoulos, A. et al. GreenGate-a novel, versatile, and efficient cloning system for plant transgenesis. PLoS ONE 8, e83043 (2013).

62. Edelheit, O., Hanukoglu, A. \& Hanukoglu, I. Simple and efficient sitedirected mutagenesis using two single-primer reactions in parallel to generate mutants for protein structure-function studies. BMC Biotechnol. 9, 61 (2009).

63. Clough, S. J. \& Bent, A. F. Floral dip: a simplified method forAgrobacteriummediated transformation ofArabidopsis thaliana: floral dip transformation of Arabidopsis. Plant J. 16, 735-743 (1998).

64. Livak, K. J. \& Schmittgen, T. D. Analysis of relative gene expression data using real-time quantitative PCR and the 2- $\Delta \Delta \mathrm{CT}$ Method. Methods 25, 402-408 (2001).

65. Gronenborn, B., Gardner, R. C., Schaefer, S. \& Shepherd, R. J. Propagation of foreign DNA in plants using cauliflower mosaic virus as vector. Nature 294, 773-776 (1981)

66. Schindelin, J. et al. Fiji: an open-source platform for biological-image analysis Nat. Methods 9, 676-682 (2012).

67. Hara, K., Kajita, R., Torii, K. U., Bergmann, D. C. \& Kakimoto, T. The secretory peptide gene EPF1 enforces the stomatal one-cell-spacing rule. Genes Dev. 21, 1720-1725 (2007).

68. Held, L. The harmonic mean $\chi 2$-test to substantiate scientific findings. J. $R$. Stat. Soc.: Ser. C (Appl. Stat.)69, 697-708 (2020).

69. Held, L. A new standard for the analysis and design of replication studies. J. $R$ Stat. Soc.: Ser. A (Stat. Soc.) 183, 431-448 (2020).

70. Crooks, G. E., Hon, G., Chandonia, J. M. \& Brenner, S. E. WebLogo: a sequence logo generator. Genome Res. 14, 1188-1190 (2004).

71. Yamaguchi, Y. L., Ishida, T. \& Sawa, S. CLE peptides and their signaling pathways in plant development. J. Exp. Bot. 67, 4813-4826 (2016).

\section{Acknowledgements}

The authors thank V. Olieric for providing beam-time and the staff at beam-line PXIII of the Swiss Light Source (SLS), Villigen, for technical assistance during data collection. Special thanks to Zachary Nimchuck (University of North Carolina) for providing us with bam1-4 bam2-4 mutant and Christian Hardtke (University of Lausanne) for the pBAM1::3xNLS::YFP reporter line. We would also like to thank Anaxi Houbaert for his input and help to set up the epidermal cell quantification, and to Yan Ma for helping us with R functions. Supported by the University of Lausanne, Swiss National Science Foundation grants no. 31003A_173101, the European Research Council (ERC) grant agreement no. 716358 and the Fondation Philanthropique Famille Sandoz.

\section{Author contributions}

A-O.R., P.J.S., and J.S. designed research; A-O.R. performed genetic, biochemical, cell biology, crystallization and phenotyping experiments. P.J.S. performed crystallization experiments, data collection, structure determination and analysis. S.A. performed genetic experiments and stomata phenotyping. C.B. performed GCI experiments and analysis. L.H. performed the statistical analysis. A-O.R. and P.J.S. wrote materials and methods and provided comments. J.S. wrote the manuscript.

\section{Competing interests}

The authors declare no competing interests.

\section{Additional information}

Supplementary information The online version contains supplementary material available at https://doi.org/10.1038/s41467-022-28558-4.

Correspondence and requests for materials should be addressed to Julia Santiago.

Peer review information Nature Communications thanks Guozhou Xu and the other, anonymous, reviewer(s) for their contribution to the peer review of this work. Peer reviewer reports are available.

Reprints and permission information is available at http://www.nature.com/reprints

Publisher's note Springer Nature remains neutral with regard to jurisdictional claims in published maps and institutional affiliations. 
(c) (i) Open Access This article is licensed under a Creative Commons Attribution 4.0 International License, which permits use, sharing, adaptation, distribution and reproduction in any medium or format, as long as you give appropriate credit to the original author(s) and the source, provide a link to the Creative Commons license, and indicate if changes were made. The images or other third party material in this article are included in the article's Creative Commons license, unless indicated otherwise in a credit line to the material. If material is not included in the article's Creative Commons license and your intended use is not permitted by statutory regulation or exceeds the permitted use, you will need to obtain permission directly from the copyright holder. To view a copy of this license, visit http://creativecommons.org/ licenses/by/4.0/.

(C) The Author(s) 2022 